NBER WORKING PAPER SERIES

\title{
OLDER AMERICANS WOULD WORK LONGER IF JOBS WERE FLEXIBLE
}

\author{
John Ameriks \\ Joseph S. Briggs \\ Andrew Caplin \\ Minjoon Lee \\ Matthew D. Shapiro \\ Christopher Tonetti \\ Working Paper 24008 \\ http://www.nber.org/papers/w24008
}

\section{NATIONAL BUREAU OF ECONOMIC RESEARCH \\ 1050 Massachusetts Avenue \\ Cambridge, MA 02138}

November 2017, Revised October 2018

This research is supported by a program project grant from the National Institute on Aging P01AG026571. Andrew Caplin, Joseph Briggs, and Christopher Tonetti acknowledge the support of the Sloan Foundation Working Longer Program for this project. This research uses data from the Vanguard Research Initiative (VRI) that was developed under the NIA program project P01-AG026571. The Vanguard Group Inc. supported the data collection of the VRI. Vanguard's Client Insight Group and IPSOS SA were responsible for implementing the VRI survey and provided substantial input into its design. The design of the VRI benefited from the collaboration and assistance of Wandi Bruine de Bruin, Alycia Chin, Mi Luo, Brooke HelppieMcFall, Ann Rodgers, and Feiya Shao, as part of the program project, and from Annette Bonner (Vanguard), Sophia Bunyaraksh (Vanguard), and Wendy O'Connell (IPSOS SA). For documentation of the VRI, including a dynamic link to the survey instrument, see http://ebpprojects.isr.umich.edu/VRI/. The views expressed herein are those of the authors and do not necessarily reflect the views of The Vanguard Group, Inc., the Federal Reserve Board, or the National Bureau of Economic Research.

At least one co-author has disclosed a financial relationship of potential relevance for this research. Further information is available online at http://www.nber.org/papers/w24008.ack

NBER working papers are circulated for discussion and comment purposes. They have not been peer-reviewed or been subject to the review by the NBER Board of Directors that accompanies official NBER publications.

(C) 2017 by John Ameriks, Joseph S. Briggs, Andrew Caplin, Minjoon Lee, Matthew D. Shapiro, and Christopher Tonetti. All rights reserved. Short sections of text, not to exceed two paragraphs, may be quoted without explicit permission provided that full credit, including $\odot$ notice, is given to the source. 
Older Americans Would Work Longer If Jobs Were Flexible

John Ameriks, Joseph S. Briggs, Andrew Caplin, Minjoon Lee, Matthew D. Shapiro, and

Christopher Tonetti

NBER Working Paper No. 24008

November 2017, Revised October 2018

JEL No. E24,J22,J26

\section{ABSTRACT}

Older Americans, even those who are long retired, have strong willingness to work, especially in jobs with flexible schedules. For many, labor force participation near or after normal retirement age is limited more by a lack of acceptable job opportunities or low expectations about finding them than by unwillingness to work longer. This paper establishes these findings using an approach to identification based on strategic survey questions (SSQs), purpose-designed to complement behavioral data. These findings suggest that demand-side factors are important in explaining late-in-life labor market behavior and need to be considered in designing policies aimed at promoting working longer.

John Ameriks

The Vanguard Group, Inc.

PO Box 2600, MS V36

Valley Forge PA 19482

john_ameriks@vanguard.com

Joseph S. Briggs

Federal Reserve Board of Governors

20th Street and Constitution Avenue N.W.

Washington, D.C. 20551

joseph.s.briggs@frb.gov

Andrew Caplin

Department of Economics

New York University

19 W. 4th Street, 6th Floor

New York, NY 10012

and NBER

andrew.caplin@nyu.edu
Minjoon Lee

Department of Economics

Carleton University

Ottawa, ON K1S 5B6

Canada

minjoon.lee@carleton.ca

Matthew D. Shapiro

Department of Economics

University of Michigan

611 Tappan $\mathrm{St}$

Ann Arbor, MI 48109-1220

and NBER

shapiro@umich.edu

Christopher Tonetti

Graduate School of Business

Stanford University

655 Knight Way

Stanford, CA 94305

and NBER

tonetti@stanford.edu 


\section{Introduction}

In many advanced economies, the share of the population that is of standard working ages 20-64 is projected to fall significantly in the coming decades (Gruber and Wise, 1998, 2007, OECD, 2006). This shift poses several economic challenges, notably increased financial strain on public pension and healthcare programs. ${ }^{1}$ In response, many countries are starting to enact or at least consider policies that encourage older workers to work longer. The appropriate policy depends on whether lack of employment beyond historically normal retirement ages more reflect the supply side of the labor market - i.e., older workers' unwillingness to work under market and institutional incentives - or the demand side -i.e., employers' unwillingness to provide work arrangements that older workers desire. Yet the relative importance of supply and demand factors remains elusive because there is no obvious behavioral imprint of frustrated desires. Little is known about the opportunity sets generating observed retirement behavior, and many of the choices are confounded by shocks, such as to the physical health of workers or financial health of firms.

In this paper, we introduce an approach to separating supply- and demand-side forces using strategic survey questions (SSQs). The SSQ responses indicate that older Americans have a strong willingness to work, especially in jobs with flexible schedules. Using this information, we estimate a key structural parameter in a model of retirement behavior, the intertemporal elasticity of substitution of labor supply (IES).

SSQs are stated preference questions purpose-designed to complement available behavioral data on labor market outcomes. Building on previous work using similar types of survey questions (Barsky, Juster, Kimball and Shapiro, 1997, Ameriks, Caplin, Laufer and van Nieuwerburgh, 2011, Ameriks, Briggs, Caplin, Shapiro and Tonetti, 2017, 2018), we designed the SSQs to be comprehensible and meaningful to respondents. These SSQs do not confound a desire to work with perceived job opportunities. They directly control for job opportunities in hypothetical situations, which allows us to identify willingness to work independent from what workers expect to find available in the actual labor market. Indeed, we pose questions that allow us to estimate willingness to work in arrangements that may not currently be prevalent, involving, in particular, a flexible schedule. The SSQ approach is particularly useful in the context of late-in-life work where the gap between the desired and available opportunities may play an important role. In particular, given the evidence on part-time options being relatively more common among post-career bridge jobs (Maestas, 2010 and Rupert and Zanella, 2015) or self-employment (Ramnath, Shoven, and Slavov, 2017), we seek to answer whether older workers would take up jobs with flexible schedules even if that is not part of their current opportunity set.

We implemented the SSQs in the Vanguard Research Initiative (VRI), a panel of American Vanguard clients more than 55 years old. The VRI sample is healthier, wealthier, and more educated than the general population of older Americans and most respondents work or worked in occupations that do not require much physical strength. Since physical deterioration is not a main force limiting work of the VRI sample, it is a particularly useful sample for studying the motives for continued work that are the focus of this paper.

\footnotetext{
${ }^{1}$ See Fuchs (1984), De Nardi, Imrohoroglu, and Sargent (1999), Lee and Skinner (1999), Kotlikoff, Smetters, and Walliser (2002), and Attanasio, Kitao, and Violante (2007).
} 
We find that older individuals would work longer, especially if schedules were flexible. Based on the SSQs, many people would take the option to work fewer hours, even if it involved a more than proportional reduction in earnings. Even those who are long retired have strong willingness to work, especially in a job with a flexible schedule.

- About 40 percent of respondents that were not working at the time of the survey, mostly in their late $60 \mathrm{~s}$ or $70 \mathrm{~s}$, are willing to work again if all the conditions were the same as their last job, including the hourly wage, the total number of hours, and the type of job.

- Willingness to work becomes much stronger if they can choose the number of hours worked instead of having to work the same number of hours as in their last job. About 60 percent of non-working respondents would be willing to return to work with such a flexible schedule. Furthermore, 20 percent of them would be willing to take more than a 20 percent hourly wage reduction to do so.

This preference for a flexible work schedule is also consistent with actual labor-market transitions of VRI respondents: A flexible schedule is more common in post-career, pre-retirement bridge jobs than in career jobs and is commonly reported as a desired characteristic in respondents' post-career job searches.

If individuals would be willing to work longer were jobs flexible, what then explains the low equilibrium incidence of part-time work late in life? The findings from the SSQs on labor supply strongly support the possibility that employers do not find it profitable to employ older workers laterin-life on part-time schedules. Even though the paper does not have direct evidence on labor demand, its price and quantity findings from the supply side quantify the strength of the demand-side factors needed to explain why the modal U.S. worker transitions directly from full-time work to complete retirement.

To relate the paper's findings to equilibrium labor-market outcomes, we use the SSQs to estimate parameters of the late-in-life labor supply model developed in Rogerson and Wallenius (2013, RW hereafter). Many workers directly transition from a full-time career job to complete retirement. Preferences for smoothing leisure would imply a more gradual decline in labor supply. The RW model addresses the challenge this work pattern poses to standard theories of labor market outcomes. In the RW model, a preference for a smooth lifecycle profile of leisure consumption, and therefore distaste for abrupt retirement, can be overcome by either a large IES or a nonconvexity in production that discourages part-time employment. As RW note, separately identifying these two factors is difficult, and the IES values estimated from retirement transitions critically depend on the strength of the assumed nonconvexities. In addition to providing new measures of willingness to work, the SSQs are by design particularly informative of structural parameters that govern late-in-life labor market behavior. Our estimates suggest preferences for smoothing labor that are generally in line with prior estimates, providing further evidence that a lack of acceptable job opportunities, likely due to a nonconvexity in production, accounts for the discrete labor force exits. Furthermore, by directly estimating the IES using SSQs, we place bounds on the size of the production nonconvexities needed to explain observed labor market life-cycle patterns. 
The remainder of the paper is structured as follows. In Section 2 we provide an overview of our sample and survey, and analyze the observed late-in-life labor market behavior of our sample, focusing on evidence that flexibility in the work schedule is associated with working longer. Section 3 introduces the SSQs and documents the reservation wages at which workers would accept job offers of various types. In Section 4 we address the challenge of separately identifying demand- and supply-side factors based on the RW model and use the SSQs to place bounds on the nonconvexities on the production side that discourage part-time work. We discuss related literature in Section 5. Section 6 concludes.

\section{Labor Market Activity After a Career Job: The Role of Flexible Schedules}

In this section we first introduce the sample and survey used in this paper. We then present the main findings from our measures of historical employment and job search that speak to older Americans' interests in post-career employment and the role of flexible schedules in promoting working longer.

\subsection{Sample and Survey}

This paper uses the Vanguard Research Initiative (VRI), a linked survey-administrative data panel drawn from account holders at The Vanguard Group, Inc., a leading investment management company. The VRI is composed of a sample of account holders at Vanguard who are at least 55 years old, have at least $\$ 10,000$ in their Vanguard accounts (to ensure their non-trivial engagement with Vanguard), and have internet access enabling them to complete the online surveys. See Ameriks, Caplin, Lee, Shapiro and Tonetti (2014) for more detailed descriptions of the sample selection criteria, summaries of demographic and financial variables, and comparison to other data sets.

VRI Survey 4, which studies labor market participation and retirement, is the primary data source for this paper. ${ }^{2}$ This survey consists of two parts. The first gathers a detailed history of employment and search behavior, extending the job history battery from the Health and Retirement Survey (HRS) to cover retirement paths and employment in post-career bridge jobs. The second section of the survey comprises the SSQs, which we analyze in Section 3.

This study uses the 2,772 respondents who completed VRI Survey 4. Appendix A provides selected sample characteristics (Appendix Table A.1) as well as a comparison of the VRI to the HRS (Appendix Table A.2). The VRI sample is on average wealthier, healthier, and more educated than a representative population. These differences diminish considerably when compared to the HRS subsample that meet the VRI sample selection criteria. Forty-one percent of the HRS respondents in the age range meet the VRI sampling restrictions (HRS respondents are "VRI eligible" if they have financial assets greater than $\$ 10,000$ and have internet access). This subsample of the HRS is slightly less educated and less healthy than the VRI. Because VRI participants remain healthier longer and have higher human capital (as proxied by education), this sample represents a population strata that likely remain

\footnotetext{
${ }^{2}$ VRI Survey 4 was administered in October 2015. See http://ebp-projects.isr.umich.edu/VRI/survey_ overview.html for more details on this and all other VRI surveys.
} 
productive longer and for whom understanding sudden labor force withdrawals is particularly policy relevant.

Table 1 presents summary statistics on respondents' employment status (by age) at the time of the survey. For those who are employed, it also shows whether they are working in a career job or a bridge job, where a career job is defined as the longest or main job respondents held after age 40 and a bridge job is any job held after leaving a career job. ${ }^{3}$ For those who are not employed, it shows whether they report being retired or not. We observe a significant increase in non-employment between ages 60 and 65, the primary ages at which individuals qualify for public and private pensions. The vast majority of those that are not employed report that they are retired. The decrease in the employment rate over age is mainly driven by the decrease in the share of respondents working in their career jobs. Employment status patterns look broadly similar to those of the general population except that the share of respondents working in a bridge job is higher in the general population. ${ }^{4}$

Table 1: Employment status

\begin{tabular}{|c|c|c|c|c|c|c|}
\hline \multirow[b]{3}{*}{ Employed (\%) } & \multicolumn{5}{|c|}{ By Age } & \multirow[t]{2}{*}{ Total } \\
\hline & $\underline{55-59}$ & $\underline{60-64}$ & $\underline{65-69}$ & $\underline{70-74}$ & $\underline{75+}$ & \\
\hline & 83.5 & 64.5 & 32.9 & 19.8 & 10.8 & 35.3 \\
\hline In a career job $(\%)$ & 64.1 & 44.8 & 17.3 & 7.8 & 4.4 & 21.7 \\
\hline In a bridge job (\%) & 19.4 & 19.7 & 15.6 & 12.0 & 6.4 & 13.6 \\
\hline Not employed (\%) & 16.5 & 35.4 & 67.0 & 80.3 & 89.2 & 64.7 \\
\hline Retired (\%) & 11.7 & 33.3 & 65.8 & 79.3 & 88.3 & 63.1 \\
\hline Not retired (\%) & 4.8 & 2.1 & 1.2 & 1.0 & 0.9 & 1.6 \\
\hline$N$ & 273 & 522 & 646 & 632 & 699 & 2,772 \\
\hline
\end{tabular}

Next, we turn to the characteristics of the career jobs held by the VRI sample. One key job characteristic we focus on in this paper is flexibility in work schedule. A job is defined to offer a flexible schedule if the worker has the ability to change either the number of hours per week or the number of weeks per year worked. Therefore, we focus on the ability to change the length of work, not the timing of work (which days or which weeks). To measure whether respondents worked in jobs with flexible schedules we asked:

If you wanted to work a different regular work schedule, would your employer (business) have allowed you to change your regular hours per week?

\footnotetext{
${ }^{3}$ When respondents have multiple bridge jobs, the survey focuses on the most recent one.

${ }^{4}$ See Appendix Table A.3 for comparison to the HRS. The career job in the HRS is defined solely based on the length of tenure, i.e., as the longest job respondents had in their life, because the survey does not provide information on subjective importance of the jobs they had. A part of the difference in the incidence rates of a bridge job may come from this difference in the definition of the career job.
} 
If you wanted to work a different regular work schedule, would your employer (business) have allowed you to change your regular weeks per year?

Table 2 presents key characteristics of career jobs of the VRI sample for those who retired from their career jobs and those who are still working on their career jobs. Most of the career jobs are full time jobs. The most common number of working hours is 2,080 per year, which is 40 hours per week for 52 weeks. Note that the average salary of those who are still working tends to be lower due to a reduction in hours for some workers. More than half of the sample worked in their career jobs for more than 20 years. The most common industry is professional, scientific, and technical services while the most common occupation is management. Few are self-employed. Having a flexible work schedule is rare. In short, this paper examines labor market transitions of those who were mainly employed on

long, full time career jobs that are typically professional and not physically demanding, and typically had no flexibility in their schedules. We find similar career job characteristics for the VRI-eligible HRS sample (see Appendix Table A.5).

The career job characteristics are overall similar between those who have already quit their career jobs and those who are still working on their career jobs, though the latter group is more likely to be self-employed and more likely to have a flexible schedule. This may be confounding two effects. On the one hand, it may be due to selection along job characteristic dimensions that encourage working longer. On the other hand, those who are still working are also more likely to be in younger cohorts and those characteristics might be related to that cohort. These confounding effects are demonstrated by the fact that those who are still working on their career jobs, compared to those who already quit their career jobs, tend to be younger but at the same time tend to stay on those jobs until older.

To disentangle these factors, we examine career job characteristics for those who are still working on their career jobs over different age groups (see Appendix Table B.1). The share of workers with a flexible schedule goes up from $36 \%$ before age 63 to $71 \%$ after age 65 . The share of self-employment changes from $9 \%$ to $24 \%$ between these two age groups. These findings show that it is primarily the selection effect that makes these characteristics more common among those who are still on their career jobs compared to those who have already quit them. This, in turn, suggests that these characteristics are preferred by older workers and hence encourage them to work longer, consistent with the findings by Ramnath, Shoven, and Slavov (2017). Appendix B.1 presents more detailed descriptions of career job characteristics by age groups.

\subsection{Labor Market Activity After a Career Job: Lessons from Bridge Jobs Held and Search Behavior}

In what follows we document three main findings from our measures of historical employment and job search behavior. First, about half of the sample who have separated from their career jobs either had a post-career bridge job or at least looked for such an opportunity. Second, bridge jobs are much more likely to have a flexible work schedule compared to career jobs. Third, flexibility in work schedule was the most popular job characteristic among those who searched for a bridge job. These findings suggest a significant willingness to work beyond a career job and an important role of flexibility in work schedule in encouraging working longer. 
Table 2: Career job characteristics

\begin{tabular}{|c|c|c|c|c|c|c|}
\hline \multirow[t]{2}{*}{ A. Retired from career job } & \multicolumn{6}{|c|}{ Age, years worked, salary, hours worked } \\
\hline & 10p & $25 p$ & $50 p$ & $75 p$ & $90 p$ & Mean \\
\hline Age: & 60 & 64 & 69 & 75 & 79 & 70 \\
\hline Age when left: & 50 & 55 & 60 & 63 & 67 & 59 \\
\hline Years worked: & 8 & 14 & 22 & 31 & 37 & 22 \\
\hline Salary (in 2015\$): & 30,866 & 58,253 & 91,467 & 133,398 & 196,379 & 111,698 \\
\hline Hours worked (per year): & 1,260 & 1,924 & 2,080 & 2,184 & 2,600 & 2,027 \\
\hline Self-employed: & $\begin{array}{l}\text { Yes } \\
\text { No }\end{array}$ & & & & & $\begin{array}{c}6.9 \% \\
93.1 \%\end{array}$ \\
\hline Had a flexible schedule: & $\begin{array}{l}\text { Yes } \\
\text { No }\end{array}$ & & & & & $\begin{array}{l}27.6 \% \\
72.4 \%\end{array}$ \\
\hline Health insurance provision: & $\begin{array}{l}\text { Yes } \\
\text { No }\end{array}$ & & & & & $\begin{array}{l}86.2 \% \\
13.8 \%\end{array}$ \\
\hline Most common industries: & \multicolumn{5}{|c|}{$\begin{array}{l}\text { Professional, scientific, and technical services } \\
\text { Manufacturing } \\
\text { Educational services }\end{array}$} & $\begin{array}{l}17.8 \% \\
14.5 \% \\
12.7 \%\end{array}$ \\
\hline Most common occupations: & \multicolumn{5}{|c|}{$\begin{array}{l}\text { Management } \\
\text { Education, training, library } \\
\text { Business and financial operations }\end{array}$} & $\begin{array}{l}25.6 \% \\
10.6 \% \\
9.8 \%\end{array}$ \\
\hline \multirow[t]{2}{*}{ B. Working on career job } & \multicolumn{6}{|c|}{ Age, years worked, salary, hours worked } \\
\hline & 10p & $25 p$ & $50 p$ & $\underline{75 p}$ & $90 p$ & $\underline{\text { Mean }}$ \\
\hline Age: & 58 & 59 & 62 & 66 & 72 & 63 \\
\hline Years worked: & 8 & 14 & 21 & 30 & 38 & 22 \\
\hline Salary (in 2015\$): & 14,089 & 44,000 & 78,000 & 117,000 & 165,000 & 92,428 \\
\hline Hours worked (per year): & 480 & 1,664 & 2,080 & 2,080 & 2,600 & 1,842 \\
\hline Self-employed: & $\begin{array}{l}\text { Yes } \\
\text { No }\end{array}$ & & & & & $\begin{array}{l}15.9 \% \\
84.1 \%\end{array}$ \\
\hline Had a flexible schedule: & $\begin{array}{l}\text { Yes } \\
\text { No }\end{array}$ & & & & & $\begin{array}{l}47.7 \% \\
52.3 \%\end{array}$ \\
\hline Health insurance provision: & $\begin{array}{l}\text { Yes } \\
\text { No }\end{array}$ & & & & & $\begin{array}{l}72.0 \% \\
28.0 \%\end{array}$ \\
\hline Most common industries: & $\begin{array}{l}\text { Profes: } \\
\text { Manuf } \\
\text { Educat }\end{array}$ & $\begin{array}{l}\text { ional, } \\
\text { acturin } \\
\text { ional s }\end{array}$ & cientific & and tec & cal services & $\begin{array}{l}18.6 \% \\
10.7 \% \\
10.5 \%\end{array}$ \\
\hline Most common occupations: & $\begin{array}{l}\text { Manag } \\
\text { Busine } \\
\text { Compr }\end{array}$ & $\begin{array}{l}\text { ement } \\
\text { ss and } \\
\text { iter an }\end{array}$ & mancial & $\begin{array}{l}\text { operatic } \\
\text { atical }\end{array}$ & & $\begin{array}{c}19.1 \% \\
11.3 \% \\
9.0 \%\end{array}$ \\
\hline
\end{tabular}

Notes: $\mathrm{N}=2,149$ for Panel $\mathrm{A}$ and $\mathrm{N}=601$ for Panel B. 


\subsubsection{Bridge Jobs}

Though a sudden withdrawal from the labor force around typical retirement ages is the most common retirement pattern in our sample, a significant fraction of the sample work beyond age 65 either on their career job or a bridge job. ${ }^{5}$ Of 2,772 respondents, we find that 2,149 respondents have separated from their career jobs, with 811 of these individuals engaging in a post-career bridge job. Given that some might still return to the labor market, this is clearly a lower bound. Hence, the $38 \%$ of VRI respondents that had a bridge job in the VRI is roughly comparable to the $52 \%$ of HRS respondents documented in Maestas (2010).

Characteristics of bridge jobs and how they compare to those of career jobs hint at which job characteristics are valued by older Americans. Table 3 compares characteristics of bridge jobs and career jobs for the respondents who had a bridge job. There are several notable patterns. First, both wages and hours of bridge jobs are lower than those of the career job for the majority of observations (Panel A). Second, in Panel B, we observe that bridge jobs are more likely to be self-employed (23\%, compared to $6 \%$ in career jobs) and more likely to have a flexible work schedule (54\%, compared to $24 \%$ in career jobs). The increase in the share of jobs with a flexible work schedule comes from the fact that $36 \%$ of observations moved from a career job with a non-flexible schedule to a bridge job with a flexible schedule, while the share of transitions from a career job with a flexible schedule to a bridge job with a non-flexible schedule is only $6 \%$ (Panel $\mathrm{C}$ ). Third, bridge jobs are much less likely to provide health insurance (Panel B). In particular, the share of bridge jobs providing health insurance is lower above age 65 (35\%, compared to $54 \%$ below age 65$)$, when workers become eligible for Medicare. Taken together, Table 3 suggests that older workers want to move to jobs with less burdensome work and greater flexibility in work schedule and that they are willing to accept a decrease in earnings and benefits.

The above patterns are consistent with workers' preference for more flexible employment. It could be, however, that workers transitioning to post-career employment move to industries and occupations that incidentally have more flexibility. We indeed observe that a significant fraction of bridge jobs entail a change in industry $(43.6 \%)$ or occupation $(35.1 \%)$, though major changes in occupation characteristics are less common (Table 4 , Panel A). ${ }^{6}$

To address these confounding effects, we examine whether the likelihood of obtaining work schedule flexibility in a bridge job depends on whether the worker changed industry or occupation (Table 4, Panel B). Those who change either industry or occupation are indeed more likely to have a flexible schedule on bridge jobs, but the effect is quite small. Slightly more than half gained flexibility when they changed industry (51\%) or occupation (53\%). The numbers are smaller but similar for those who stayed in the same industry $(44 \%)$ or in the same occupation $(44 \%)$. Changing occupation category does not significantly affect the likelihood of gaining work schedule flexibility. In Appendix B.2 we

\footnotetext{
${ }^{5}$ Recall that the survey defines the career job as the longest and most important job held since age 40 . The survey asks about one subsequent job (if any) - either the current job for those still working or the last job. We define this post-career job as the bridge job for this analysis.

${ }^{6}$ To examine changes in occupation characteristics, we classify occupations into three categories based on the type of abilities most required per occupation: human capital, social capital, and physical strength. The classification is based on a principal component analysis on the list of required abilities from ONET.
} 
Table 3: Comparison: bridge jobs vs. career jobs

\begin{tabular}{|c|c|c|c|c|c|c|c|}
\hline \multicolumn{8}{|c|}{ A. Hours and Earning } \\
\hline & \multicolumn{6}{|c|}{ Ratio of Bridge/Career } & \\
\hline & $10 p$ & $25 \mathrm{p}$ & $50 p$ & $75 \mathrm{p}$ & $90 p$ & Mean & \\
\hline Hours & $\overline{0.06}$ & $\overline{0.21}$ & $\overline{0.74}$ & $\overline{1}$ & $\overline{1}$ & 0.65 & \\
\hline Hourly wage & 0.19 & 0.44 & 0.80 & 1.14 & 1.7 & 1.06 & \\
\hline Annual salary & 0.03 & 0.10 & 0.44 & 0.87 & 1.18 & 0.54 & \\
\hline \multicolumn{8}{|c|}{ B. Job Characteristics, Career to Bridge } \\
\hline \multicolumn{2}{|c|}{$\begin{array}{c}\text { Self- } \\
\text { Employed }\end{array}$} & & \multicolumn{2}{|c|}{$\begin{array}{l}\text { Flexible } \\
\text { Schedule }\end{array}$} & & \multicolumn{2}{|c|}{$\begin{array}{c}\text { Health Insurance } \\
\text { Provided }\end{array}$} \\
\hline Career & Bridge & & Career & Bridge & & Career & Bridge \\
\hline $6.4 \%$ & $23.3 \%$ & & $24.0 \%$ & $53.5 \%$ & & $87.8 \%$ & $41.0 \%$ \\
\hline \multicolumn{8}{|c|}{ C. Gaining/Losing Work Schedule Flexibility } \\
\hline \multirow{4}{*}{$\begin{array}{c}\text { Career Job } \\
\text { Schedule }\end{array}$} & \multirow{4}{*}{$\begin{array}{c}\text { Flexible } \\
\text { Not Flexible }\end{array}$} & & \multicolumn{2}{|c|}{$\begin{array}{c}\text { Bridge Job } \\
\text { Schedule }\end{array}$} & & & \\
\hline & & & Flexible & Not Flexible & & & \\
\hline & & & $17.6 \%$ & $6.4 \%$ & & & \\
\hline & & & $36.0 \%$ & $40.0 \%$ & & & \\
\hline
\end{tabular}

Notes: $\mathrm{N}=812$. Characteristics of career versus bridge jobs for respondents with bridge jobs. Winsorization at $1 \%$ and $99 \%$ levels is used in calculating the mean values.

provide a more detailed analysis of the transitions between industries and occupations on the one hand and changes in the share of flexible jobs within each industry and occupation on the other hand, confirming this broad finding. We conclude that changes in industry or occupation do not fully explain the increased prevalence of flexible schedules in bridge jobs.

\subsubsection{Job Search after Career Job}

The willingness to work reflected in the actual job histories analyzed above is likely underestimated, both because some workers may still find post-career-job employment after we fielded the survey and because some workers who desired a bridge job might not have been able to find one. To provide further insight into willingness to work and more information on the job characteristics that are desired and not just found, we turn now to job search behavior. ${ }^{7}$

\footnotetext{
${ }^{7}$ Faberman, Mueller, Sahin, and Topa (2017) also field an original survey to study job search behavior. Their focus is on the differences in search behavior and labor market outcomes between employed and non-employed individuals.
} 
Table 4: From career to bridge jobs: changes in occupation, industry, and flexibility

\section{A: Changes in Industry/Occupation}

$\begin{array}{lcc} & \underline{\text { Yes }} & \underline{\text { No }} \\ \text { Changed Industry } & 43.6 \% & 56.4 \% \\ \text { Changed Occupation } & 35.1 \% & 64.9 \% \\ \text { Changed Occupation Category* } & 26.7 \% & 73.3 \%\end{array}$

\section{B: Fraction Who Gained Flexibility}

\begin{tabular}{|c|c|c|c|c|c|c|}
\hline & \multicolumn{2}{|c|}{$\begin{array}{l}\text { Changed } \\
\text { Industry }\end{array}$} & \multicolumn{2}{|c|}{$\begin{array}{c}\text { Changed } \\
\text { Occupation }\end{array}$} & \multicolumn{2}{|c|}{$\begin{array}{c}\text { Changed } \\
\text { Occ. Category }\end{array}$} \\
\hline & $\underline{\text { Yes }}$ & $\underline{\text { No }}$ & $\underline{\text { Yes }}$ & $\underline{\text { No }}$ & $\underline{\text { Yes }}$ & $\underline{\text { No }}$ \\
\hline Gained Flexibility: & $51.1 \%$ & $44.3 \%$ & $53.0 \%$ & $44.3 \%$ & $47.7 \%$ & $46.6 \%$ \\
\hline Stayed Fixed-Schedule: & $48.9 \%$ & $55.7 \%$ & $47.0 \%$ & $55.7 \%$ & $52.3 \%$ & $53.4 \%$ \\
\hline
\end{tabular}

Notes. Panel A tabulates the share of workers who changed industry, occupation, or occupation category between career and bridge jobs. It includes every respondent who had a bridge job $(\mathrm{N}=812)$.

Panel B calculates the share of respondents who obtained flexibility in work schedule in the bridge job, conditional on whether they changed industry/occupation or not. The panel includes the subset who did not have a flexible schedule in their career jobs $(\mathrm{N}=617)$.

*We define three broad occupation categories based on the type of abilities most required per occupation: human capital, social capital, and physical strength. The classification is based on a principal component analysis on the list of required abilities from ONET.

Among those who directly transitioned to complete retirement after their career jobs, only $11 \%$ (147 out of 1,336) report having looked for a new job opportunity. In contrast, 80\% (657 out of 812) of those who had a bridge job actively looked for such an opportunity, while only $20 \%$ of those found their bridge job without reporting searching. Thus, most workers who report having searched actively successfully found employment. This suggests either that most older non-workers are not interested in post-career employment or that they are not interested in the jobs they believe they would be likely to find.

Table 5 summarizes what job characteristics individuals looked for when they searched. We find further suggestive evidence that flexibility is an important characteristic for workers pursuing bridge jobs: $40 \%$ want flexibility in deciding the number of hours and $31 \%$ want flexibility in how to allocate these hours. Furthermore, 33\% want less responsibility, suggesting pursuit of jobs that are less burdensome, while $30 \%$ want to be more of their own boss. We also find strong heterogeneity in what older workers look for - there is no single characteristic that is searched for by more than $40 \%$, and all considered characteristics, except for better health insurance, are searched for by at least $10 \%$ of the sample. 
Table 5: Search behavior: what workers looked for

\begin{tabular}{|c|c|}
\hline Characteristic & \% looked for \\
\hline \multicolumn{2}{|l|}{ Change life: } \\
\hline$\overline{\text { Different industry }}$ & 23.5 \\
\hline Different occupation & 27.4 \\
\hline Move to a better location & 20.8 \\
\hline \multicolumn{2}{|l|}{ Flexibility: } \\
\hline More flexible hours & 39.9 \\
\hline More flexible schedule & 31.0 \\
\hline \multicolumn{2}{|l|}{ Autonomy: } \\
\hline$\overline{\text { Less responsibility }}$ & 32.5 \\
\hline More of my own boss & 29.7 \\
\hline \multicolumn{2}{|l|}{ Other job characteristics: } \\
\hline More pay & 19.9 \\
\hline Less commuting time & 25.1 \\
\hline More job security & 15.3 \\
\hline Better health insurance & 7.8 \\
\hline
\end{tabular}

Notes: $\mathrm{N}=804$. Respondents who searched after career job.

Overall, these findings echo those from analyzing bridge jobs held. Flexibility appears to be an important factor among those considering working after their career jobs.

\subsubsection{Summary}

From our measures of employment history and job search behavior we derive the following two main findings. First, about half of our sample reveal an interest in working after exiting a career job by either searching for or securing such employment. Second, when searching for post-career employment, older workers prioritize flexibility in their work schedule. Hence, we find a significant desire for post-career employment in general and for a bridge job with a flexible work schedule in particular. Still, about half of the sample retired from a career job without even looking for a post-career employment opportunity. This, however, does not necessarily imply that these respondents are not interested in working longer, as their behaviors also reflect their perception of available jobs in the market. Direct measurement of labor supply preferences requires controlling for demand-side factors, which is achieved in the SSQs introduced in the next section.

\section{Measurement of Willingness to Work Using SSQs}

In this section, we introduce and analyze measures of individual preferences for supplying labor. The SSQs we pose directly control for job opportunities in hypothetical situations. This approach allows us 
to identify willingness to work independent of what workers expect to or are able to find in the actual labor market. By measuring labor supply in different working environments, we can quantify workers' interest in considered job characteristics. In particular, we focus on the role of flexibility in schedule, defined as the ability to change the number of regular working hours, in encouraging working longer. By comparing how willingness to work varies depending on the number of working hours, the SSQs also allow us to infer a labor-supply parameter that is crucial in retirement decisions, the intertemporal elasticity of labor supply (IES, see Section 4 for the estimation of the IES). In addition to presenting details of SSQ design and the information they contain on willingness to work, we also present a number of internal and external validation checks on the responses.

\subsection{Design of SSQs}

The SSQs considered in this paper all have a similar structure. The SSQs ask respondents that are currently not working ("non-workers" hereafter) whether or not they would accept a hypothetical job opportunity. Characteristics of the hypothetical job offer are based on a "reference job," which is constructed based on the characteristics of the most recent job the respondent had (recorded from the first part of the survey). Hence, the reference job is the career job for those who did not have a bridge job and it is the last bridge job for those who had a bridge job. Anchoring hypothetical job opportunities to the job characteristics from actual work history helps respondents put themselves in the hypothesized situation and also links their SSQ responses to the actual choices they have made.

We use four SSQs that differ in characteristics of the job or in timing of the job offer. For the job characteristics, we focus on whether the job allows a flexible schedule or not. In the "fixed schedule" scenario, the number of hours is fixed to that which respondents worked in the last year of their reference job. In the "flexible schedule" scenario, the respondents are allowed to choose the number of hours. Jobs with fixed and flexible schedules are hypothetically made available at two points of time, at the moment of the survey and at the moment of retirement from the reference job. ${ }^{8}$

For each job offer, the SSQ first asks whether the respondent would accept it if the salary were the same as that in the reference job and then elicits the respondents reservation wage. ${ }^{9}$ If the respondent accepts the job offer, the SSQ further asks for the lowest salary at which the respondent would still accept the offer. If the respondent rejects the job offer, the SSQ further asks for the lowest salary at which the respondent would switch to accepting the offer. This reservation wage allows us to quantify a respondent's willingness to work in each circumstance.

We illustrate key features of the SSQs by presenting one in detail: A job with a fixed schedule available at the moment of the survey. At the beginning of the question, the following text is shown to the respondents:

\footnotetext{
${ }^{8}$ Additional SSQs were asked but not used in this paper. See Appendix C for the complete list of the SSQs and detailed scenarios.

${ }^{9}$ Under the flexible schedule scenario, the offered salary varies proportionally with the chosen number of hours.
} 
In the questions that follow, we are interested in what you would choose if you were to have certain decisions to make about your employment situation. While the choices that we describe are hypothetical, we ask you to do your best to assess what you would choose if you were to face these choices today.

In the scenario that follows, you will be asked to make a choice between Options A and B. Option A will be to immediately accept a specified employment opportunity that will be open only for a short window (say one week) and will then become unavailable. Option B is instead to pursue other possibilities including searching for another employment situation or not working.

- Option A is a new employment situation that involves a fixed work schedule. Other than this possible difference, the new employment situation matches your reference employment situation in terms of occupation, annual earnings, and all other characteristics.

- Option B is instead to pursue other possibilities including searching for another employment situation or not working.

To better clarify the situation, the question provides additional details:

- Option A matches your reference employment situation not only in terms of occupation, annual earnings, and current work schedule, but also in all other aspects that are important to you that are not specified in the above table [that summarizes the reference job characteristics].

- If you choose Option B, Option A is no longer available.

- If you choose Option A you will be able at any later point to quit and to pursue other possibilities, including searching for another employment situation or not working.

- Pay in Option A changes over time as you would expect it to in your reference position.

- [Omitted if single] In this choice and in all that follow, please suppose that your spouse behaves in a manner that is consistent with your choices. If your spouse's employment situation would differ depending on whether you choose Option A or Option B, please take this dependence into account in answering the question.

Then the respondent is asked to choose between Option A and Option B. A respondent who chose Option A (Option B) is further asked: ${ }^{10}$

\footnotetext{
${ }^{10}$ Feldstein and Poterba (1984), Holzer (1986), and Krueger and Mueller (2016) use a similar survey approach to elicit the reservation wages of unemployed workers.
} 
- Starting at the reference salary, imagine that earnings for Option A were to decline (increase). What earnings level for Option A would be just low (high) enough that you would switch to Option B (Option A)?

Respondents are allowed to skip the SSQs, but conditional on completing the survey the item non-response rate to the SSQs is almost zero. There are 1,771 non-workers who answered all four of the SSQs used in this paper. We divide this group further into those who never had a bridge job and those who had a bridge job because these two groups may have different preferences for labor supply and because the reference job is qualitatively different across these two groups. There are 1,337 non-workers without a bridge job and 434 respondents with a bridge job. The reference job is the career job for those who did not have a bridge job and it is the last bridge job for those who had a bridge job.

\subsection{Willingness to Work at the Time of the Survey}

In this subsection, by using the SSQs with hypothetical job opportunities that are available at the time of the survey, we confirm that older Americans have a strong willingness to work longer. This strong desire to work is present even if they cannot choose the number of hours they work. Futhermore, allowing a flexible work schedule boosts people's willingness to work significantly.

\section{Fixed Schedule Scenario}

Even in the fixed schedule scenario, in which respondents have to work the same number of hours as in their reference job, the acceptance rate is fairly high. The blue (darker) bar in Figure 1 plots the acceptance rate in this scenario. About one third of non-workers with no bridge job (Panel A) accept this offer while 44 percent of those who had a bridge job (Panel B) accept it. Acceptance means that the respondent would come back to the labor market at a salary that is the same as in the reference job. The acceptance rate for the former group is surprisingly high, given that the vast majority of them (89 percent) did not even search for a new job opportunity after leaving their career jobs (and had not returned to work at the time of the survey). This demonstrates that, at least for these individuals, they are not working not because of their lack of interest in working, but because of a (perceived) lack of job opportunities that are as attractive as their reference jobs. A non-negligible fraction of the respondents are willing to work even at a lower wage than that they used to earn. Twenty percent of those who did not have a bridge job and $30 \%$ of those who did are willing to accept a $10 \%$ wage reduction to work in the hypothesized situation. Even with a $20 \%$ wage reduction, some respondents (10\% and $20 \%$ respectively for each group) are still willing to work.

\section{Flexible Schedule Scenario}

When the hypothetical offer adds flexibility by allowing the respondent to adjust the number of working hours, willingness to work increases significantly. The yellow (lighter) bar in Figure 1 shows the increase in the acceptance rate in the flexible schedule compared to the fixed schedule. When the schedule is flexible, at the reference hourly wage, more than half of the sample would accept the offer. 
Figure 1: Would current non-workers return to work?

A. Had no bridge job

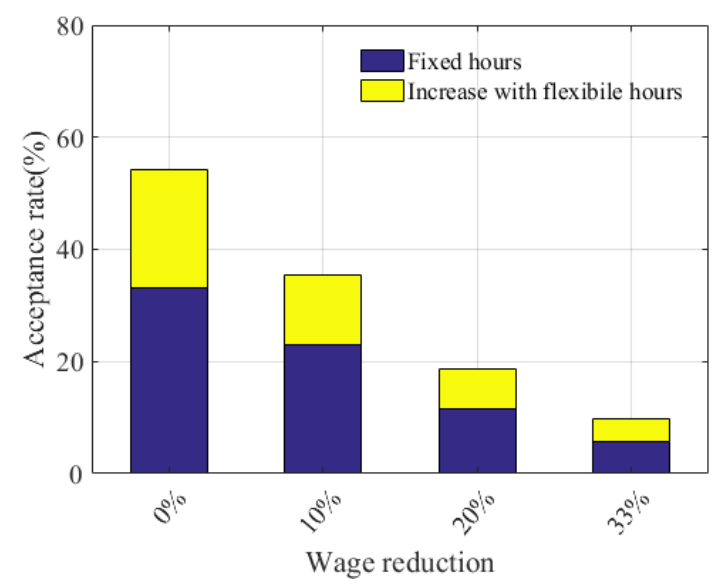

B. Had a bridge job

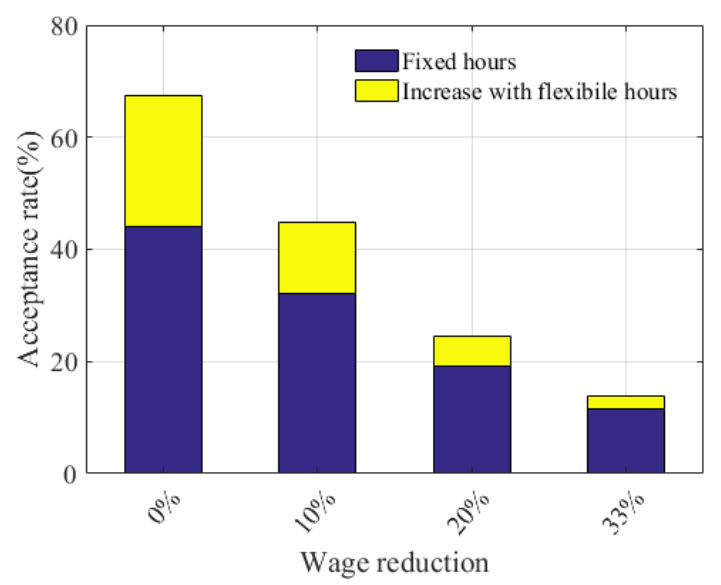

Note: $\mathrm{N}=1,337$ for Panel A and 434 for Panel B. Wage reduction is calculated relative to the wage of the reference job. The blue (darker) bars represent the acceptance rates under a fixed schedule scenario and the yellow (lighter) bars represent the increases in the acceptance rates with a flexibility in the work schedule.

This is half as many again as with the fixed schedule. The increase in the acceptance rate in both groups is about 20 percentage points. This means that $20 \%$ of individuals did not want to work under a fixed schedule at this hourly wage, but were willing to work at the same hourly wage if they could choose the number of hours. Moreover, many are willing to accept a significant wage reduction as long as they can choose their own work schedule. About $10 \%$ more non-workers are willing to take a $10 \%$ wage reduction compared to the fixed schedule scenario, for example.

Figure 2 presents the full distribution of the reservations wages, normalized as a fraction of the individual's reference job wage. For any value of the reservation wage between $50 \%$ and $150 \%$ of the reference wage, the acceptance rate is higher (i.e., the CDF is higher) when the offer comes with a flexible schedule. In both scenarios, the slope of the distribution, and hence the extensive margin elasticity, is the largest going from $70 \%$ to $100 \%$ of the reference wage.

Conditional on accepting the offer with a flexible schedule at the reference hourly wage, we find an overall tendency to reduce work, with a large degree of heterogeneity in the desired change in hours worked (Table 6, Panel A). The median respondent (whether they had a bridge job or not) wants about $10 \%$ fewer hours than the reference schedule, showing that for most non-workers, their preference for a flexible work schedule is associated with a modest desired reduction in the number of hours.

\subsection{Willingness to Work at the Time of Retirement from the Last Job}

The second set of SSQs concern hypothetical job opportunities that were made available at the time of retirement from their last job (i.e., immediately after they separated from their last job). ${ }^{11}$ These

\footnotetext{
${ }^{11}$ For those who retired within the last two years, the survey did not ask this set of SSQs because for them the situation at the time of retirement is too similar to that at the time of the survey.
} 
Figure 2: Reservation wage distribution of current non-workers

A. Had no bridge job

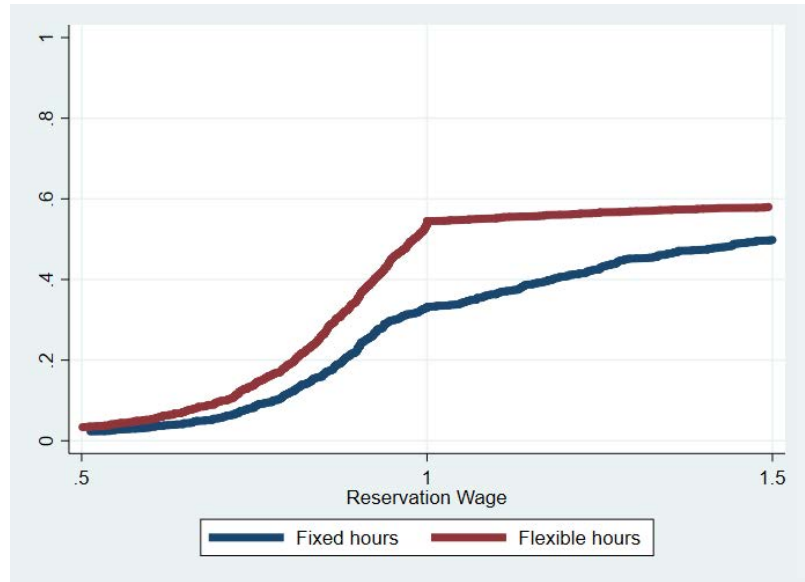

B. Had a bridge job

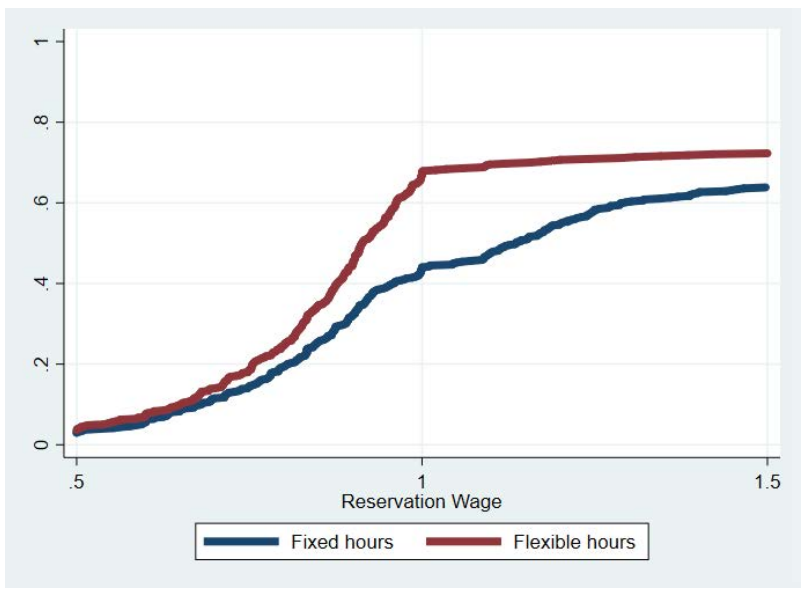

Note: Reservation wage is calculated as a fraction of the wage the respondent had in their reference job. The figure plots the CDF of reservation wages in the range between 0.5 and 1.5 .

Table 6: Desired reduction in hours (\%)

\section{A. Time of the Survey}

$\begin{array}{lcccccc} & \underline{\mathbf{1 0 p}} & \underline{\mathbf{2 5 p}} & \mathbf{5 0 p} & \underline{\mathbf{7 5 p}} & \underline{\mathbf{9 0 p}} & \underline{\mathbf{N}} \\ \text { Had no bridge job } & -15.4 & 0 & 11.4 & 44.6 & 69.6 & 710 \\ \text { Had a bridge job } & -11.8 & 0 & 9.4 & 39.7 & 62.5 & 291\end{array}$

$\begin{array}{lccccccc}\text { B. Time of retirement } & & & & & \\ & \underline{\mathbf{1 0 p}} & \underline{\mathbf{2 5 p}} & \underline{\mathbf{5 0 p}} & \underline{\mathbf{7 5 p}} & \underline{\mathbf{9 0 p}} & \underline{\mathbf{N}} \\ \text { Had no bridge job } & -2.9 & 0 & 19.2 & 50.0 & 71.2 & 545 \\ \text { Had a bridge job } & 0 & 0 & 7.7 & 27.3 & 50.0 & 294\end{array}$

Notes: This table includes respondents who would accept the offer of a flexible schedule at the reference hourly wage.

questions aim to investigate which hypothetical job opportunities would have changed their decision to stop working.

Figure 3 summarizes the acceptance rates from the fixed and flexible schedule scenarios. Overall patterns are similar to those for job opportunities made available at the time of the survey. Even when the offer does not allow for any flexibility in schedule, the acceptance rate is fairly high at the reference wage. It is $30 \%$ for those who retired from their career jobs and $60 \%$ for those who retired from their bridge jobs. Some individuals would have been willing to take a significant wage reduction if they could have had such a job opportunity right after they left their last job. 20\% of those who retired from their career jobs and $40 \%$ of those who retired from their bridge jobs would have been willing to take at least a $10 \%$ wage reduction. 
Figure 3: Would current non-workers have continued to work?

A. Had no bridge job

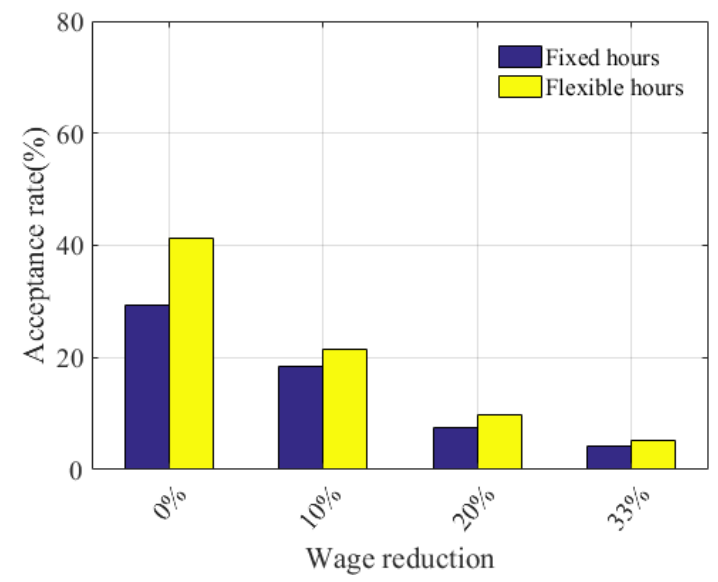

B. Had a bridge job

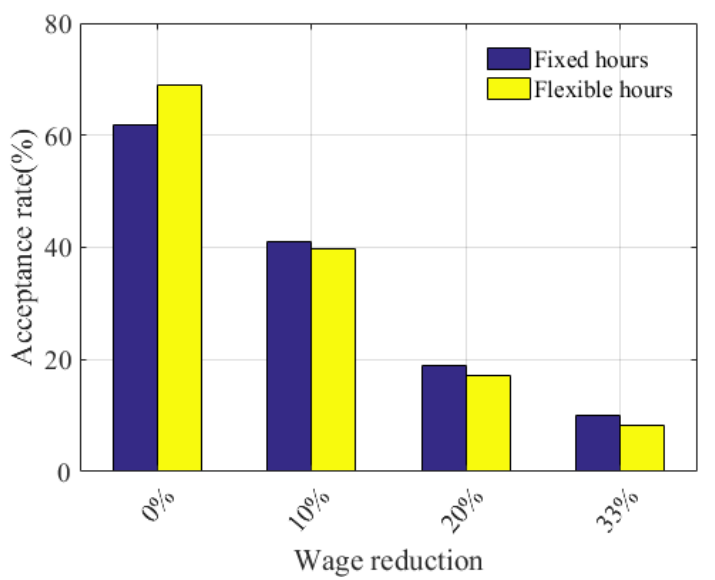

Note: $\mathrm{N}=1,226$ for Panel A and 432 for Panel B. Wage reduction is calculated relative to the wage of the last job.

Allowing for a flexible schedule again increases willingness to work, but the effect is smaller at the time of retirement than at the time of the survey. At the reference wage, flexibility increases the acceptance rate by 10 percentage points for both groups compared to the fixed schedule scenario, which is still significant but smaller than the 20 percentage point increase we saw from the questions that offered jobs at the time of the survey. The effect is even smaller when there is a wage reduction of $10 \%$ or more.

For those who did not have a bridge job, the smaller effect is due to a lower acceptance rate for a job with a flexible schedule at the time of retirement. This may suggest a certain amount of burn-out (Maestas and Li, 2007, Jacobs and Piyapromdee, 2016): some respondents did not even want to work part-time immediately after leaving their career job. Indeed, the acceptance rate for the opportunity with a flexible schedule at the time of the survey was $10 \%$ lower for those who stopped working less than two years ago compared to those who stopped working more than two years ago, further suggesting burn-out. On the other hand, for those whose reference job is a bridge job, the smaller effect is due to a higher acceptance rate for a fixed schedule job. This may suggest that they had already adjusted hours as desired in the bridge job. ${ }^{12}$ These patterns are also clear from the full distribution of the reservation wages (Figure 4). At the time of retirement (the solid curves), reservation wages tend to be lower when the offer comes with a flexible schedule, but the gap between the two curves is smaller than that from the time of the survey (the dashed curves). The extensive margin elasticity is again the largest from $70 \%$ to $100 \%$ of the reference wage.

\footnotetext{
${ }^{12}$ Conditional on being willing to accept the offer at the reference hourly wage, the desired reduction in working hours at the time of retirement is slightly larger for those who retired from a career job and slightly smaller for those who retired from a bridge job, compared to the desired reduction at the time of the survey (Table 6, Panel B).
} 
Figure 4: Reservation wage distribution at the time of retirement

A. Had no bridge job

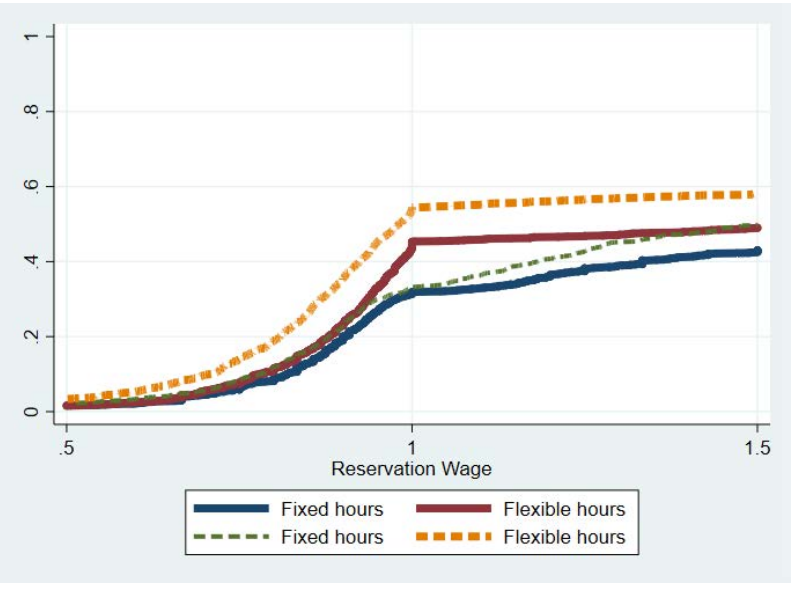

B. Had a bridge job

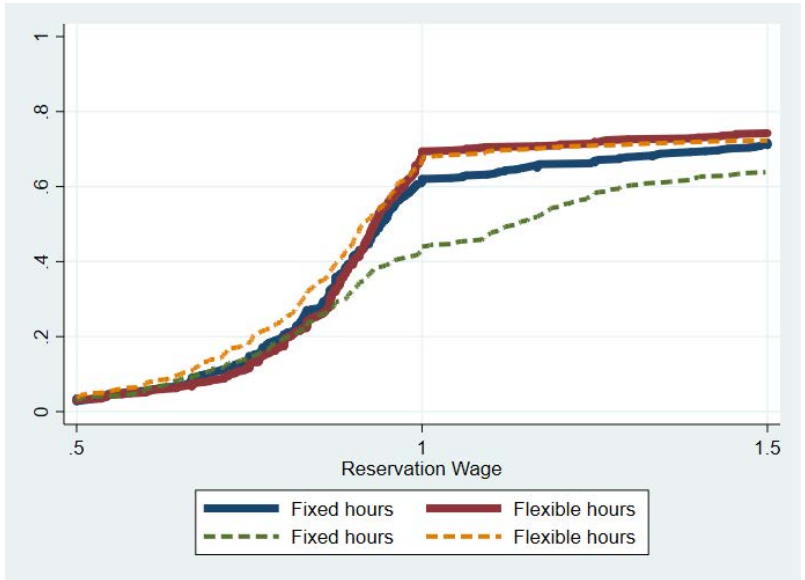

Note: Reservation wages are calculated as a fraction of the wage respondents had in their reference jobs. The figure plots the $\mathrm{CDF}$ of reservation wages in the range between 0.5 and 1.5. The figure also shows the distributions for job offers at the time of the survey for the corresponding scenarios and groups in dashed curves for comparison.

\subsection{Robustness and Credibility}

Credibility of the findings in this paper hinges on the quality of responses to the SSQs. In the absence of a pecuniary incentive to elicit truthful and accurate survey responses as is typical in field experiments (e.g., Mas and Pallais, 2017a), careful design of survey questions and ex-post tests on responses are necessary to make sure that respondents paid enough attention to and understood the hypothesized situations and also that the responses reflect true preferences as manifested in measured behavior. As part of the survey design, we implemented a pilot survey with a small sample who provided us detailed feedback on the SSQs that helped improve the main survey. In addition, we support credibility of the SSQ responses using a number of internal and external consistency tests. This subsection reports the results from two external consistency tests, which show that the SSQ responses are related to certain observed behaviors in a reasonable manner. Appendix E reports additional credibility results, including tests that document a within-person internal consistency of responses and comprehension tests that show respondents understood the hypothetical situation and questions.

\subsubsection{Search Behaviors and SSQ Responses}

As external validation, we examine whether the SSQ responses are consistent with respondents' actual post-career-job search behavior. Table 7 compares the acceptance rate of the offer under different scenarios at the time of the survey, for respondents grouped based on their search behavior. ${ }^{13}$ Allowing

\footnotetext{
${ }^{13}$ We run this test only for the non-workers who did not have a bridge job. For those who had a bridge job, what they were looking for after quitting the career job, e.g., fewer working hours, might have already been reflected in the bridge job they actually had, which serves as the reference job in the SSQ. If that is the case, offering further flexibility in the SSQ may have limited effect for them.
} 
for a flexible schedule in the SSQs indeed had the largest impact on those who actually searched for a flexible schedule. The increase in the acceptance rate due to flexibility in work schedule for that group (36 percentage points) is larger than that for those who never searched (18 percentage points) and for those who searched for other job characteristics (20 percentage points). Despite the small sample size of the first group, the increase in the acceptance rate for that group is significantly different from that for those who never searched at the 5 percent level. Appendix E.1 confirms a similar pattern from the search for another job characteristic that is not the focus of this paper. The consistency between the SSQ responses and actual search behavior suggests that the SSQ responses contain information on individuals' true preferences.

Table 7: Search behaviors and SSQ responses: acceptance rate at the time of the survey

\begin{tabular}{lccc}
\hline \hline & $\mathbf{N}$ & \multicolumn{2}{c}{ Acceptance rate } \\
\cline { 3 - 4 } Searched for & & $\underline{\text { Fixed }}$ & Flexible \\
Did not search & 1,188 & 33.7 & 51.5 \\
Flexibility & 63 & 34.9 & 71.4 \\
Other than flexibility & 84 & 33.3 & 64.3 \\
& & & \\
\hline \hline
\end{tabular}

Notes: The tabulation includes only non-workers who did not have a bridge job.

\subsubsection{Reasons for Separation and SSQ Responses}

The first part of the survey includes a battery of questions adapted from the HRS concerning the reasons why individuals separated from their previous jobs. Respondents are asked to choose the most important reason from options such as retirement, family obligation, health issues, etc. Most nonworkers (in particular 90\% of those who did not have a bridge job) report that they quit to retire. ${ }^{14}$ Yet, some indicate that they were forced to leave the job by reporting reasons such as being laid off, discharged, and employer closing or selling the business.

In Table 8 we compare the SSQ responses between those who were forced to leave their previous job (defined as those who report any of "laid off," "discharged," "employer closed business," and "employer sold business" as the main reason for the separation) and those who were not forced to leave the previous job (defined as the compliment of the former, most of them reporting "retirement" as the main reason). We expect those who were forced to leave their last job to be more likely to accept an offer made at the time of that separation. Table 8 confirms that this is indeed the case. In both fixed and flexible schedule scenarios at the time of retirement, the acceptance rate is higher for those who report being forced to leave their last job. The difference is larger for those who did not have a

\footnotetext{
${ }^{14}$ We debated whether or not to include retirement on the list of choices because it obscures the reason for separation, but for comparability with the HRS we did include it.
} 
bridge job. This pattern is consistent with those who were forced to leave their job having wanted to continue to work if they could find a reasonably good offer while those who were not forced to leave having wanted to have at least some time off.

Table 8: Reasons for separation and SSQ responses: acceptance rate at the time of retirement

\begin{tabular}{lllllc}
\hline \hline Group & Separation reason & & Fixed & Flexible & N \\
\cline { 2 - 2 } No bridge job & $\begin{array}{l}\text { forced to leave } \\
\text { not forced to leave }\end{array}$ & 50.4 & 57.0 & 130 \\
& 29.9 & 43.1 & 1,105 \\
\multirow{2}{*}{ Had a bridge job } & $\begin{array}{l}\text { forced to leave } \\
\text { not forced to leave }\end{array}$ & 67.0 & 73.0 & 100 \\
& & & 66.6 & 334 \\
\hline \hline
\end{tabular}

Notes: A separation is classified as forced if the respondent mentioned any of "laid off," "discharged," "employer closed business," and "employer sold business."

It may seem puzzling that $30 \%$ of people who do not report being forced to leave their career job would, at the moment of separation, accept a job offer with similar characteristics to their career job and a fixed work schedule. It is possible that, even though they report not being forced to leave, they were experiencing negative changes in working conditions or anticipating such declines. To examine this possibility, we use a question from the first part of the survey that asks whether respondents experienced any change in working conditions around the moment of a job separation, regardless of whether they were the main reasons for retirement or not. The share of those who experienced any negative changes in working conditions is higher among those who would accept the job offer with a fixed schedule (21\%) than those who would not (10\%). ${ }^{15}$ In addition, $22 \%$ of those who would accept the job offer report that they had a special early retirement incentive offer ( $18 \%$ for those who would not). Taken together, this additional evidence provides potential reasons why many in this sample decided to leave their career jobs even if they remained willing to work under the same conditions.

\subsection{Summary}

The SSQs allow us to identify a strong and prevalent willingness to work among older Americans. One third of current non-workers in the VRI report being willing to work again at the time of the survey, even if they could not choose the number of hours worked, as long as they could find a job that has similar characteristics to the last job they had. Many of them also report being willing to take a significant wage reduction to have such a job opportunity. The estimated willingness to work is much stronger than that which can be inferred from the behavioral data only. In particular, of all the people who transitioned directly from working in a career job to not working at all, only $11 \%$

\footnotetext{
${ }^{15}$ Individuals are defined to have experienced negative changes in working conditions if they report any of the following: "supervisor encouraged departure," "coworker encouraged departure," "waged reduced (or about to be reduced)," "would have been laid off," "new job duties," or "new job location." Other options included in the question are "hours reduced," "became eligible for a pension," "employer changed health insurance," and "special early retirement incentive offer."
} 
searched for work after quitting their career job, but one third would be willing to work again in a job with similar characteristics to their career job. This difference between labor market outcomes, labor search behavior, and reported desire to work demonstrates the importance of controlling for demand-side factors, or workers' perceptions of those factors, in measuring willingness to work late in life.

The SSQs suggest that older workers have a strong preference for flexibility in their work schedules. Allowing for flexibility not only increases the acceptance rate at the reference wage (by 20 percentage points at the time of the survey), it also increases the wage reduction workers are willing to accept. This suggests that the increase in the share of jobs with a flexible schedule among bridge jobs documented in the previous section is at least in part driven by workers' preferences.

Strong willingness to work is not confined to a specific age group. Indeed we find that the acceptance rates in each scenario are fairly similar across all the age groups where we have dense observations (i.e., ages 60-80). This again suggests that demand-side factors play an important role in explaining the sudden withdrawal from the labor force of individuals in their mid to late $60 \mathrm{~s}$. We also find that acceptance rates do not significantly vary with wealth across the wide range of wealth in the VRI sample. This suggests that the strong willingness to work documented in this paper is not confined just to those with substantial financial savings in late life.

Though the SSQs are asked with hypothetical job opportunities, tests of the credibility of the responses suggest that such purpose-designed questions can elicit useful information about respondents' true preferences.

\section{IES Estimation Using the SSQs}

SSQ responses indicate a stronger preference for reduced hours and greater flexibility among older Americans than observed retirement patterns imply. Furthermore, as highlighted in Rogerson and Wallenius (2013, RW hereafter), the prevalence of abrupt retirements is puzzling in the context of standard models of labor supply in which individuals prefer to smooth leisure utility. In RW's model strong enough production nonconvexities or a large enough intertemporal elasticity of substitution of labor supply (IES) are able to generate abrupt retirements. As emphasized by RW, patterns of abrupt retirement are not enough to separately identify the strength of production nonconvexities and the IES. In this section we show how to identify the IES independent of production nonconvexities by combining SSQ responses with RW's model. We then estimate the IES for each respondent and calculate the strength of production nonconvexities needed to explain typical retirement patterns. Our estimates suggest IES values slightly towards the high end, but within the range, of previous estimates that use micro data. These values of the IES provide further evidence that demand side constraints or production nonconvexities are responsible for the prevalence of abrupt labor force exits.

We first document the relationship between production nonconvexities, the IES, and hour-profiles/labor force exit, as well as the challenge in identifying the IES in the presence of nonconvexities. We show that SSQ responses identify the IES independent of production nonconvexities and then present our estimated IES distribution. Finally, as a credibility check, we show that the IES estimates are negatively 
correlated with searching for flexible jobs, as expected.

\subsection{The Identification Problem with Behavioral Data Alone}

The IES is a key parameter in studying retirement behavior, as it determines how individuals want to allocate the hours they work over their lifetime. An individual with a low IES wants to smooth hours worked over time, while an individual with a high IES is comfortable with highly variable hours worked over the life cycle, including possibly periods of full time work and full retirement.

As noted in RW, there is an inconsistency between the low IES commonly estimated in micro studies and that typically needed in models to rationalize observed retirement behavior: generating an abrupt retirement requires an IES much larger than one, but most of the empirical studies (leveraging labor supply responses to tax changes) suggest an IES much smaller than one (see Keane, 2011, for a survey). To reconcile this inconsistency, RW propose introducing a nonconvexity in production that limits workers' desire to choose to work part-time en route to labor force exit. Of course, this suggests that inferring the IES from behavioral data is contingent on the assumed strength of the production nonconvexity. In fact, any observed retirement behavior can be rationalized by any value of the IES for some freely-chosen production nonconvexity.

The model used in RW is as follows. In their model with age-dependent preferences and wages, nonconvexity in production, and time and expenditure fixed costs of work, a household chooses $c_{t}$ and $h_{t}$ to solve:

$$
\begin{aligned}
& \max \int_{t=0}^{T}\left[U\left(c_{t}\right)+\alpha_{t} \frac{\left(1-e \bar{h}-h_{t}\right)^{1-1 / \gamma}}{1-1 / \gamma}\right] d t \\
& \text { s.t. } \int_{t=0}^{T}\left(c_{t}+e \bar{c}\right) d t=\int_{t=0}^{T}\left(w_{0, t} h_{t}^{\theta}\right) h_{t} d t+Y,
\end{aligned}
$$

where $t$ is the age subscript, $h_{t}$ is the amount of labor supplied (normalized as a fraction of the total time endowment), $\gamma$ parameterizes the intertemporal elasticity of substitution for leisure, $\alpha_{t}$ is the weight on utility from leisure, $e$ is an indicator function for currently working, $\bar{h}$ and $\bar{c}$ are time and expenditure fixed costs of working, and $Y$ is total life-time resources other than labor earnings. Let $w_{t}=w_{0, t} h_{t}^{\theta}$ denote the hourly wage. $\theta$ is the elasticity of wage to hours and controls the strength of the nonconvexity in production and $w_{0, t}$ is the scalar that anchors the age-profile of wages. The hourly wage is an increasing function of the number of hours worked, which captures the disadvantage to part-time working. Given the amount of labor supplied, $\gamma$ pins down the IES by:

$$
I E S:=\frac{\mathrm{d} h_{t} / h_{t}}{\mathrm{~d} w_{t} / w_{t}}=\gamma \frac{1-e \bar{h}-h_{t}}{h_{t}}
$$

For simplicity, it is assumed that there is no uncertainty, no time discounting, and that the interest rate is zero. This model abstracts from some factors that might be relevant to workers near normal retirement ages, including Social Security and pension benefit accrual, burn out, and human capital. In Section 4.5, we discuss how inclusion of these factor would affect the main results of the current section. 
Suppose that either $\alpha_{t}$ is increasing or $w_{0, t}$ is decreasing over age. Then households would want to work more when younger and less when older. More importantly, given the values of the fixed costs of working $(\bar{c}$ and $\bar{h})$, if the IES is high or the nonconvexity in production $(\theta)$ is strong, then this incentive is sufficiently strong to generate a direct transition from working full-time to retirement.

To be more specific, suppose we want to generate the typical retirement pattern from this model that at certain age, say $t=r$, a worker who was working $h_{r}$ number of hours, suddenly transitions into no work. For $r$ to be the optimal retirement age, the following first order condition needs to be satisfied at that age:

$$
U^{\prime}\left(c^{*}\right)\left(w_{0, r} h_{r}^{1+\theta}-\bar{c}\right)=\alpha_{r}\left(\frac{1}{1-1 / \gamma}-\frac{\left(1-e \bar{h}-h_{r}\right)^{1-1 / \gamma}}{1-1 / \gamma}\right),
$$

where $c^{*}$ is equal to lifetime labor earnings plus $Y$ under the assumption that $U(\cdot)$ represents a preference for consumption smoothing and a normalization of $T=1$. The left hand side of equation (4) is the marginal benefit to working longer and the right hand side is the marginal cost. In addition, for $h_{r}$ to be the optimal number of working hours at $r$, the following first order condition needs to be satisfied:

$$
U^{\prime}\left(c^{*}\right)(1+\theta) w_{0, r} h_{r}^{\theta}=\alpha_{r}\left(1-e \bar{h}-h_{r}\right)^{-1 / \gamma}
$$

The left hand side is the marginal benefit to increasing hours worked and the right hand side is the marginal cost. By dividing both sides of these two first order conditions, we obtain the exact value of $\theta$ that is just large enough to generate a direct transition from working $h_{r}$ hours to no work: ${ }^{16}$

$$
\theta=(1-\hat{c}) h_{r}(1-1 / \gamma) \frac{1}{\left(1-\bar{h}-h_{r}\right)^{1 / \gamma}\left(1-\left(1-\bar{h}-h_{r}\right)^{1-1 / \gamma}\right)}-1 .
$$

This equation relates the IES and $\theta$. When the IES is higher, the household is more sensitive to the financial disincentives associated with part-time working (the fixed costs and nonconvexity in production), so it is more discouraged from working part-time and more likely to choose a direct transition to retirement. In addition, when $\theta$ is higher, the hourly wage reduction associated with part-time work is larger, so the household faces a larger disincentive to part-time working. Thus, for a higher $\theta$, direct retirements can be rationalized with a lower value of the IES.

Figure 5 presents this trade-off graphically by plotting equation 6 , with the shaded region corresponding to the parameter space that can generate abrupt retirement from full-time work. ${ }^{17}$ Following RW, we assume that the fixed cost of working in terms of foregone leisure is $4 \%$ of the time endowment $(\bar{h}=0.04)$ and the fixed cost in terms of expenditure is $14 \%$ of full-time earnings $(\hat{c}=0.14)$. We use these values of fixed costs as our baseline calibration for all following exercises. ${ }^{18}$ In addi-

\footnotetext{
${ }^{16}$ Following RW, we assume the expenditure fixed cost of working $(\bar{c})$ to be proportional to labor earnings at $h_{r}$. Hence, the parameter $\hat{c}$ in equation (6) is defined as $\hat{c}=\frac{\bar{c}}{w_{0, r} h_{r}^{(1+\theta)}}$.

${ }^{17}$ Full-time work is calibrated as 2,000 hours per year, or $h_{r}=0.385$, which is common among career jobs of the VRI sample as well as the HRS sample.

${ }^{18}$ In Appendix D.2 we report results from alternative calibrations.
} 
tion to highlighting the role of the IES and nonconvexity in production in generating retirement from full-time work, this figure also reveals the identification challenge associated with using behavioral data only (the direct transition to retirement in this case). While the observed behavior excludes certain combinations of these two factors - all of the parameter values outside of the shaded area can be ruled out - there remains a substantial area of the parameter space that can rationalize transitions from full-time work to retirement. Any value of the IES can be consistent with the observed behavior depending on the assumed value of $\theta$. For example, if $\theta$ is 0.3 , then the IES needs to be larger than 0.9 to rationalize abrupt retirement (blue line in Figure 5). But if $\theta$ is 1 , then the IES can be as small as 0.4 (red line in Figure 5). The opposite is also true: any value of $\theta$ can rationalize sudden retirement depending on the value of the IES. If we can pin down one of the two parameters using an additional source of information, then the observed behavior places bounds on the values the other parameter can take. This motivates our estimation of the IES using the SSQs.

Figure 5: Required IES and $\theta$ to generate retirement from full-time work

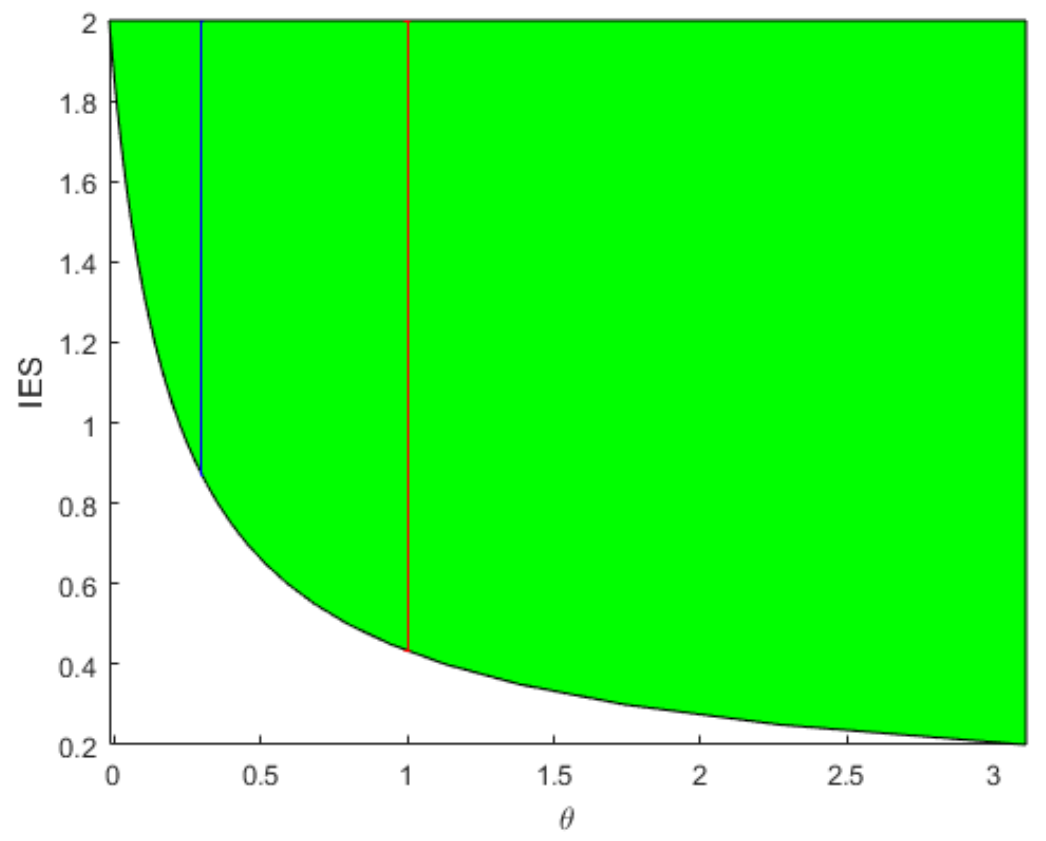

Note: The green area contains the combinations of the IES and $\theta$ that are consistent with a direct transition from full-time work to retirement when full-time work is calibrated as $h_{r}=0.385$ (2,000 hours per year). The boundary of the area corresponds to equation (6). The blue line represents values of the IES that are consistent with a direct transition if $\theta=0.4$ while the red line represents those for $\theta=1.0$.

\subsection{Identifying IES using SSQ Responses}

The SSQs collect two different wage and hour pairs (under a fixed and flexible schedule) that make an individual indifferent to working or exiting the labor market. In this section we demonstrate that 
this is sufficient to identify an individual's IES, independent of the nonconvexity in production. ${ }^{19}$ Intuitively, a small IES corresponds to a steep increase in the marginal disutility of extra work. Thus, a respondent with a smaller IES would be willing to accept a larger wage reduction in order to work fewer hours. We formally derive this relationship below.

First, suppose that $h_{\text {fixed }}$ is the number of hours respondents have to work in the fixed schedule scenario and $w_{\text {fixed }}$ is the reservation hourly wage that makes respondents indifferent between accepting this job offer and not working for the considered moment. If the marginal value of resources, $U^{\prime}\left(c^{*}\right)$, is not affected by this choice (which is a good approximation for the VRI sample because they have high financial wealth and relatively short remaining time to work), the extensive-margin indifference condition in equation (4) determines the reservation wage, $w_{\text {fixed }}$, as:

$$
U^{\prime}\left(c^{*}\right)\left(h_{\text {fixed }} w_{\text {fixed }}(1-\hat{c})\right)=\alpha_{t}\left(\frac{1}{1-1 / \gamma}-\frac{\left(1-\bar{h}-h_{\text {fixed }}\right)^{1-1 / \gamma}}{1-1 / \gamma}\right),
$$

where $\alpha_{t}$ may depend on the time the question concerns (i.e., the time of the survey or the time of retirement). The right-hand side is the foregone utility from giving up leisure to work the fixed number of hours, while the left-hand side is the value of income from this job.

Second, let $h_{\text {flex }}$ be the number of hours chosen under the flexible schedule scenario and $w_{\text {flex }}$ be the reservation hourly wage that makes respondents indifferent between accepting this offer and not working at the considered moment. At the reservation wages, utility is the same whether working a fixed or a flexible schedule, yielding the following relationship:

$$
U^{\prime}\left(c^{*}\right)\left(h_{\text {fixed }} w_{\text {fixed }}-h_{\text {flex }} w_{\text {flex }}\right)=\alpha_{t}\left(\frac{\left(1-\bar{h}-h_{\text {flex }}\right)^{1-1 / \gamma}}{1-1 / \gamma}-\frac{\left(1-\bar{h}-h_{\text {fixed }}\right)^{1-1 / \gamma}}{1-1 / \gamma}\right)
$$

where the right-hand side is the leisure cost of working longer and the left-hand side is the value of additional income from working longer. This equality holds at the reservation wages because the outside option of not accepting the offer is equal across scenarios.

By dividing equation (7) by equation (8) and rearranging terms, we get:

$$
\frac{w_{\text {flex }}}{w_{\text {fixed }}}=\frac{h_{\text {fixed }}}{h_{\text {flex }}}\left(1-\frac{(1-\hat{c})\left(\left(1-\bar{h}-h_{\text {flex }}\right)^{1-1 / \gamma}-\left(1-\bar{h}-h_{\text {fixed }}\right)^{1-1 / \gamma}\right)}{1-\left(1-\bar{h}-h_{\text {fixed }}\right)^{1-1 / \gamma}}\right) .
$$

Since we are using two questions that place the individual at the same point in time, the timevarying weight on leisure-utility $\left(\alpha_{t}\right)$ and the marginal utility of income $\left(U^{\prime}\left(c^{*}\right)\right)$ cancel out. Given the calibrated values of the fixed costs of working $(\bar{h}$ and $\hat{c})$, the only unknown variable in equation (9) is $\gamma$, so we can estimate the IES that is consistent with this condition and observed responses $h_{\text {flex }}, w_{\text {fixed }}$, and $w_{\text {flex }}$.

Equation (9) is basically an indifference curve. For a given value of the IES (or $\gamma$ ), it determines the pairs of $\left\{\frac{h_{\text {flex }}}{h_{\text {fixed }}}, \frac{w_{\text {flex }}}{w_{\text {fixed }}}\right\}$ that make the individual indifferent between working under the fixed schedule and the flexible schedule (where the level of $w_{\text {fixed }}$ satisfies equation $(7)$ ). Figure 6 plots the indifference

\footnotetext{
${ }^{19}$ See Pistaferri (2003) for an alternative identification strategy based on subjective expectations of wage growth.
} 
curves for various values of the IES. The lower is the IES, the steeper is the indifference curve. The marginal disutility of work increases faster with a lower IES, hence a worker with a lower IES would accept a larger wage reduction for a given reduction in hours. As the IES increases, the curve becomes flatter. $^{20}$ This demonstrates why the IES is a key parameter in explaining retirement behavior in RW's model: Those with a small IES highly value the option to work part-time, so unless the nonconvexity in production is strong, they will choose a part-time bridge job over abrupt retirement. On the other hand, for those with a high IES, a small penalty for part-time work is enough to discourage them from working part-time and hence to induce a transition from full-time work to complete retirement.

Figure 6: SSQ responses and IES: Indifference curves

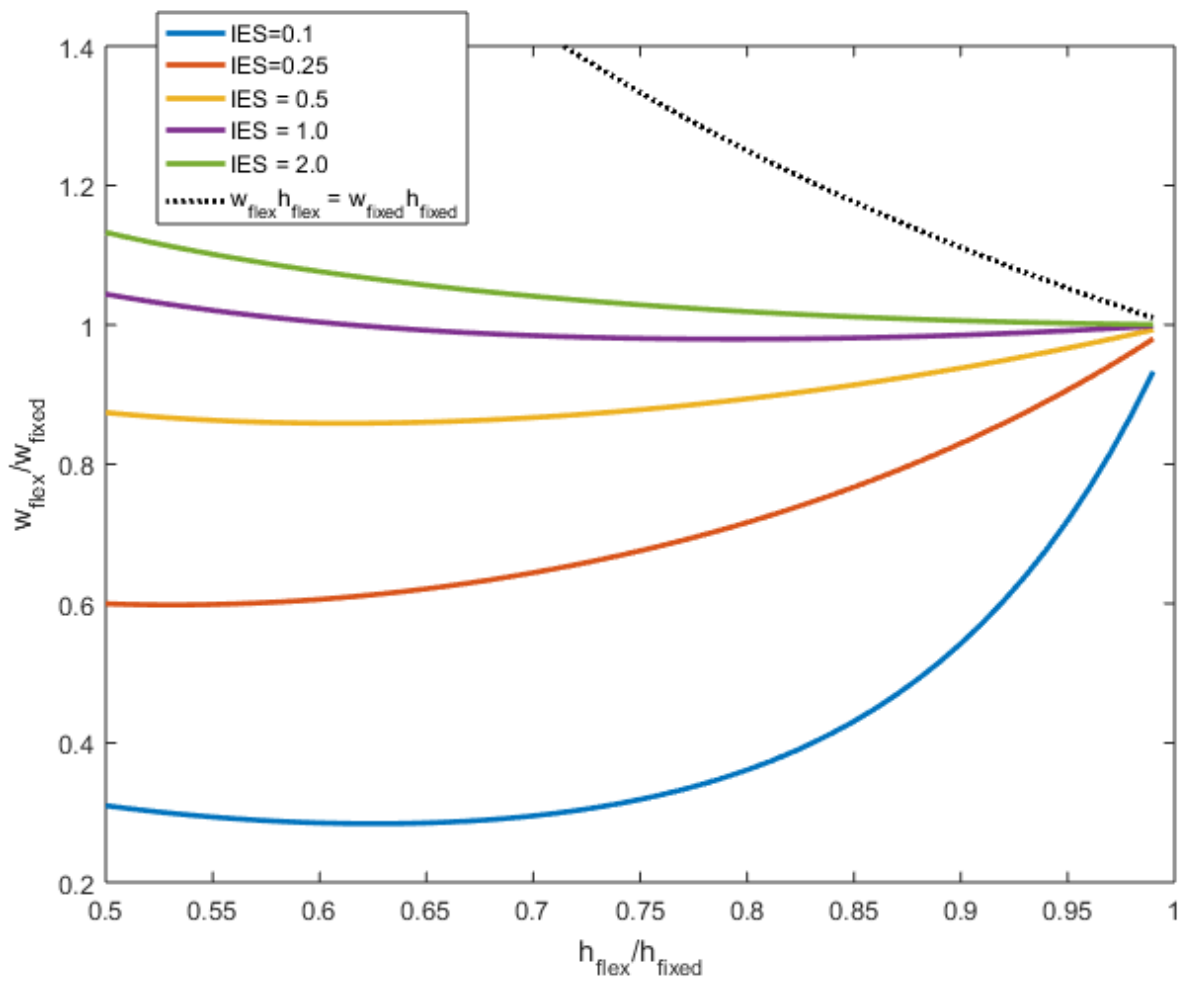

Note: Each curve connects the pairs of $\left\{\frac{h_{\text {flex }}}{h_{\text {fixed }}}, \frac{w_{\text {flex }}}{w_{\text {fixed }}}\right\}$ that make the worker with the considered value of IES indifferent between working under the fixed schedule and flexible schedule scenario, under $h_{\text {fixed }}=0.385$, $\bar{h}=0.04$, and $\hat{c}=0.14$. The figure zooms in the range $[0.5,1.0]$ for $\frac{h_{\text {flex }}}{h_{\text {fixed }}}$ where most of the responses fall.

An observed pair of $\left\{\frac{h_{\text {flex }}}{h_{\text {fixed }}}, \frac{w_{\text {flex }}}{w_{\text {fixed }}}\right\}$ from the SSQ allows us to pick which indifference curve the respondent is on. This, in turn, allows us to estimate the IES value for this respondent as the one that corresponds to the chosen indifference curve.

Some responses $\left(\left\{\frac{h_{\text {flex }}}{h_{\text {fixed }}}, \frac{w_{\text {flex }}}{w_{\text {fixed }}}\right\}\right)$ cannot be rationalized with any value of the IES. For some of these responses, we can assign them either top- or bottom-coded values of the IES, by extending the

\footnotetext{
${ }^{20}$ In the absence of fixed costs of working, the curves are always upward-sloping and they converge to the horizontal curve as the IES goes to infinity. Fixed costs of working create negative slopes to compensate for the increase in the average cost of working when the number of hours is reduced, either when the IES is very high or the reduction of the number of hours is large.
} 
logic of the RW model and allowing the fixed costs to be heterogeneous. Some respondents (4\%) choose a number of hours under a flexible schedule that is too small to be justified under the baseline fixed costs. But such responses can be rationalized with lower fixed costs and a low IES. Thus, we assign a low value of IES (0.05) to these responses. On the other hand, some respondents (10\%) demand an hourly wage increase for working fewer hours that is too large to be justified under the baseline fixed costs. Such responses can be rationalized with larger fixed costs and a high IES. We assign a high value of the IES (10) to such responses. However, those responses where total earnings from working fewer hours is greater than or equal to that from working full time $\left(w_{\text {flex }} h_{\text {flex }} \geq w_{\text {fixed }} h_{\text {fixed }}\right.$, the area above the dotted curve in Figure 6) cannot be justified under any labor supply model with a positive utility value of leisure regardless of the values of the fixed costs, so they are dropped from the analysis ( $10 \%$ of the sample).

Furthermore, some responses do not reveal relevant information for the IES estimation so they are not included in the estimation. Those who choose to reject both offers at any reasonable wage do not provide relevant information for the estimation (37\% of the sample). ${ }^{21}$ These individuals may indeed have low IES since allowing flexibility does not change their decision to retire, though it is not operational because they also have low preference for work later in life (high $\alpha_{t}$ ). Respondents who report the same number of hours and reservation wages in both scenarios provide only one effective observation, which is not enough to construct the indifference curve needed for estimation ( $10 \%$ of the sample).

\subsection{IES Estimates}

Figure 7 shows the cumulative distribution of the estimated IES under the baseline calibration of the fixed costs. ${ }^{22}$ The median IES estimates are 0.45 when using SSQs with job offers at the time of the survey and 0.83 when using SSQs with job offers at the time of retirement. These are well in line with findings from the microeconomic literature: the average among the estimates from the studies examined in Keane (2011) is 0.31. Recent works including Domeij and Floden (2006) and Chetty (2012) show that accounting for frictions such as credit constraints and adjustment costs can lead to a larger estimate: Chetty (2012) suggests 0.5 as a reasonable estimate. RW argues that under the values of the nonconvexity in production that are often used in the literature the IES needs to be at least 0.75 to explain the observed retirement behavior.

Our estimates do not depend on the strength of the nonconvexity in production. In fact, given the RW model, our estimates provide a range of the nonconvexity in production that are in line with a transition from full-time work to retirement. According to Figure 5, the median IES estimate from the offers at the time of the survey (0.45) suggests that $\theta$ needs to be larger than 0.85 to generate such a retirement pattern while that from the offers at the time of retirement (0.83) suggests a range above 0.35. Any value below this threshold is not consistent with a retirement from full-time work for more than half of the sample. For example, a worker whose IES is 0.45 and works full-time immediately before retirement would be willing to accept an $8 \%$ wage reduction to work $10 \%$ fewer hours. However,

\footnotetext{
${ }^{21}$ If the reservation wage is given in one scenario but not in the other, we assume a high reservation wage for the latter (twice of the reference wage).

${ }^{22}$ See Appendix Figure D.3 for the results from alternative calibrations.
} 
Figure 7: Distribution of IES estimates

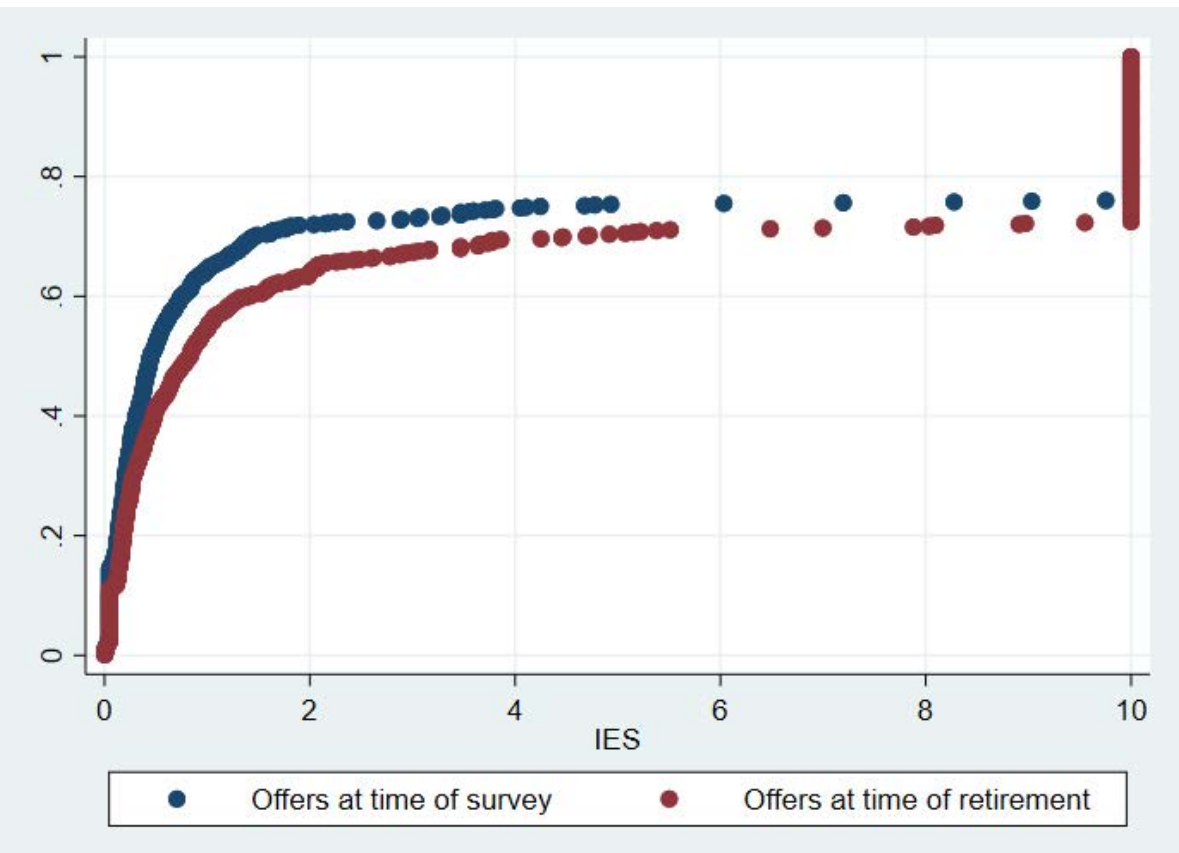

Notes: The curves represent CDFs of the estimated IES. Each point corresponds to a respondent. The horizontal axis shows the estimated IES and the vertical axis shows the share of estimates that are smaller than or equal to that value of the IES. N=796 for offers at the time of the survey and $N=668$ for offers at the time of retirement.

with $\theta=0.85$, the wage a firm is willing to pay to such a part-time worker is slightly less than that, resulting in a direct transition from full-time to no work. ${ }^{23}$

Though this is an indirect inference of which validity may be affected by elements not explicitly considered in the baseline model (see Section 4.5), the estimates obtained from the SSQs, in particular those from the offers at the time of retirement, are in line with findings from the empirical literature that uses exogenous variations in the number of hours. This literature either uses variations in hours induced by Social Security rules (Aaronson and French, 2004) or from the number of children of female workers (e.g., Rosen, 1976, Moffitt, 1984, and Ermisch and Wright, 1993). Aaronson and French (2004) find that reducing hours per week from 40 to 20 between ages 62 and 65 results in a $25 \%$ wage penalty, which implies $\theta=0.42$.

We also estimate significant heterogeneity in the IES. For about a quarter of respondents, the IES is less than 0.2 while for another quarter it is larger than 5. The former group will find part-time working attractive even when $\theta$ is as high as 3 . The latter group will choose retirement over part-time work even in the absence of the nonconvexity $(\theta=0)$ since the fixed costs are enough to discourage them from working part-time.

\footnotetext{
${ }^{23}$ Given the fixed costs and increasing marginal disutility of work, the marginal decrease in the reservation wage associated with fewer hours is larger when the number of hours is closer to full-time work. Therefore, if the only parttime option allowed is a much larger reduction in hours, say $50 \%$ fewer hours, then the value of $\theta$ needed to rationalize an abrupt retirement is only 0.25 if the $I E S=0.45$ (see also RW).
} 


\subsection{IES Estimates and Measured Search Behavior}

The RW model we build upon predicts that individuals with a smaller IES value part-time options more. Relying on this relationship, we provide evidence supporting the validity of our IES estimates by examining whether the IES estimates predict searching for flexibility, conditional on searching for a job opportunity, after a career job exit. ${ }^{24}$ To avoid confounding the analysis due to differences in reference job type (bridge vs. career), we study those who had a bridge job. ${ }^{25}$ We use Tobit to account for the top- and bottom-coding of the IES. Because the IES is right skewed, we consider a log specification.

Table 9 reports the association between the log of the IES estimates and searching for a flexible schedule controlling for key demographic variables including gender, marital status, and age, last job characteristics such as whether they had a flexible schedule or not and the number of hours, and a dummy variable for the SSQ from which the IES is estimated. The point estimate suggests that, as predicted by the model, those who searched for flexibility indeed have a smaller IES. They have on average a 50\% smaller IES than those who did not look for flexibility. Notwithstanding the small sample size, the estimate is statistically significant at the $10 \%$ level. This result provides evidence that the estimated IES distribution captures true heterogeneity in preferences that affect behavior. The other coefficients, though some with large estimated effects, are statistically insignificant. Since the IES estimates are based on SSQs that are designed to extract preferences, the insignificance of these coefficients is a desired outcome.

Table 9: IES estimates and search behavior

Variable

Searched for flexibility

Single male

Coupled male

Coupled female

Age

Number of hours in the last job

Having a flexible schedule in the last job

Social capital occupation

Physical capital occupation

SSQ at the time of retirement

\section{Coefficient Standard error}

$-0.566^{*}$

0.565

0.349

$-0.692$

0.017

$-0.000$

$-0.066$

$-0.097$

0.399

$0.963^{*}$
$(0.309)$

Note: $\mathrm{N}=363$. The dependent variable is the $\log$ of IES estimates. Tobit is used to account for top- and bottom-coding of the IES. Only those who had a bridge job are included. * indicates significance under $10 \%$ level.

\footnotetext{
${ }^{24}$ We focus on jobs they searched for instead of jobs they worked, since jobs worked are more affected by the available jobs offered in the market.

${ }^{25}$ The vast majority of those who did not have a bridge job did not search.
} 


\subsection{Robustness with Respect to Modeling Assumptions}

In this paper, we demonstrate that by using the SSQ responses and the RW model one can estimate the IES, a key supply-side parameter in explaining retirement behavior. We also show that the IES estimates provide an indirect estimate of a key demand-side parameter in the RW model, the nonconvexity in production. One might be concerned that overly-restrictive modeling choices are driving the results. Note that the RW model used for both the IES estimation and indirect inference on the nonconvexity parameter abstracts from some factors that might be relevant to workers near normal retirement ages, including Social Security and pension benefit accrual, burn out, and the accumulation and loss in human capital. In this subsection, we discuss how our main findings would be affected by inclusion of these elements in the model.

By the design of the SSQs, the IES estimates are not affected by inclusion of these elements. Recall that the IES estimates are obtained from comparing responses to two hypothetical new job offers available at the same point of time, that are identical except for the number of hours. Choices in the SSQs do not affect the pension benefits from previous jobs. Also, for workers at or above the full retirement age (66) - i.e., most of the non-worker sample - additional earnings do not affect Social Security benefits. If burn-out takes the form of an increase in $\alpha_{t}$ the IES estimates are unaffected, because burnout does not enter equation (9), the key equation for the IES estimation. $\alpha_{t}$ cancels out when we compare the fixed and flexible job offers by dividing equation (7) by equation (8) because we are comparing two offers available at the same point in time. Regarding human capital, it is unlikely that at older ages human capital accumulation provides additional incentive to work (Heckmann, Lochner and Taber 1998, Huggett, Ventura and Yaron, 2011). At these ages, what is more likely to be relevant in workers' search for a bridge job is a potential loss of firm-specific human capital. But loss of firm-specific human capital does not enter the estimation equation either because the equation is based on the reservation wages demanded by workers, not the wages that firms are willing to offer.

Indirect inference concerning the nonconvexity parameter based on the IES estimates and the RW model may be affected by inclusion of these elements to a certain extent. RW argue that the mapping between the IES and nonconvexity parameters that are consistent with observed retirement behaviors is not significantly affected by Social Security and pensions. For those who are close to or over the full retirement age, the effect of current income on the total amount of Social Security benefits is limited, because on the one hand, additional earnings do not affect the average indexed monthly earnings much at that stage, and on the other hand, workers face limited negative incentive to work even before the full retirement age under the current rule. So it plays a role similar to non-labor income $(Y)$ that is already incorporated in the model (see equation (2)). Private pensions may provide an incentive for an early retirement, as we observed in Section 3.4.2. As RW argue, however, what matters in this context is not just a return to work at the previous employer but that to work in general, where the latter is not affected by an early retirement incentive generated by private pensions from previous jobs. Burn out provides another reason for a sudden transition to no work at all, but it should be accompanied by a loss of human capital while not working to explain why retirees do not return to work after taking some time off. A loss of job-specific human capital may have a direct impact on the inference on the nonconvexity parameter. When searching for a part-time bridge job, workers may experience 
not only a wage penalty due to reduced hours but also a reduction in the wage level $\left(w_{0, t}\right)$ due to a loss of job-specific human capital. Omitting this factor may overestimate the size of the nonconvexity parameter. Our results from the offers at the time of the survey suggest a fairly large value of the nonconvexity parameter ( $\theta$ needs to be at least 1 to explain abrupt retirement for half of the sample). This finding may speak for the importance of job-specific human capital.

A different modeling issue is that we use a utility function that is separable between consumption and leisure to simplify derivations of the key equations. Neither the IES estimation from the SSQ responses nor the mapping between the nonconvexity parameter and the IES in the RW model is affected by allowing nonseparability between consumption and leisure in the utility function. We can use exactly the same equations for the IES estimation (equation (9)) and for the indirect inference on the nonconvexity parameter (equation (6)) even when the utility function is nonseparable. See Appendix D.3 for details.

\section{$5 \quad$ Related Literature}

This paper relates to a number of literatures. First, we contribute to an empirical literature that examines employment patterns late in life, both by documenting the post-career-job work history and search behavior of the VRI sample and by eliciting their willingness to work using hypothetical questions. Beginning with Ruhm (1990) and more recently documented by Maestas (2010) and Rupert and Zanella (2015), it has long been established that following a typical retirement path (i.e., direct transition from full time career job to full retirement) is becoming less common, with Cahill, Giandrea and Quinn (2006) noting that post-career employment resembles initial labor market engagement decades earlier, in terms of involving experimentation. Many of these jobs are part-time or lower paid, with the classical hump-shaped wage profile reflecting workers willingness to take lower wages for less work (Cassanova, 2013). Furthermore, many workers return to employment to gain access to employer sponsored health plans, in particular before becoming eligible for Medicare at age 65 (Madrian, Burtless and Gruber, 1994, Blau and Gilleski, 2008). Self-employment associated with fewer hours and lower earnings is also used as a transition path to full retirement (Ramnath, Shoven, and Slavov, 2017). Of course, some returns to work do not reflect workers' preferences, with Chan and Stevens (2001) noting the volatile employment of workers that are fired after age 50 and a number of studies noting the labor demand side constraints that hinder post-career employment (e.g., Hurd, 1996, Scott, 2004, Kantarci and van Soest, 2008). Our paper documents that either having a bridge job before full-retirement or searching for such an opportunity is not rare, but also that using behavioral data alone leads to under-estimation of older individuals' willingness to work.

This paper contributes to a literature that empirically examines the effect of institutional incentives on late-in-life labor supply by proposing an approach to disentangle the roles played by supply- and demand-side factors in generating the observed changes in labor market activity. Many studies in this literature rely on aggregate data leveraging cross-country differences or historical changes within countries in public pension benefit systems (see for example Blondal and Scarpetta, 1999, Gruber and Wise, 1999, Johnson, 2001, and Duval 2003). Others use variation in retirement incentives across 
households that arise from public or private pension systems and public medical insurance (see for example Blundell, Meghir and Smith, 2002, Gruber and Wise, 2002, Euwals, van Vuuren, and Wolthoff, 2012, and Gustman, Steinmeier and Tabatabai, 2016). While informative, reactions to such policy incentives still combine the older individuals' willingness to work and job availability. The results in this paper show that for a policy to be effective in encouraging working longer it should address demand-side factors.

This paper also relates to a literature that matches structural models to observed retirement patterns in order to estimate the importance of various institutions and policies in determining retirement behavior. Beginning with Berkovec and Stern (1991), a number of papers have highlighted the importance of minimum hours constraints (Gustman and Steinmeier, 1986), social security (Rust and Phelan, 1997, French, 2005, Blau and Gilleskie, 2006, Van der Klaauw and Wolpin, 2008), and public and private health insurance (French and Jones, 2011). These papers also suggests ways to overcome the identification issue associated with using only behavioral data. For example, French (2005) addresses the selection bias in estimating a wage profile for older workers by generating the same selection process in the model. Identifying all the key supply- and demand-side parameters relying only on behavioral data is still challenging and these studies have to make assumptions either on the level or distribution of certain key parameters. A prime example is the assumption on nonconvexity parameters in French (2005). Our paper contributes to this literature by providing an alternative method to separately identify supply- and demand-side structural parameters, so that a lifecycle model can provide better-informed predictions on the effectiveness of considered policies.

Finally, this paper relates to two branches of the survey literature. First, the SSQ survey instruments we use in this paper reflect a methodological approach to surveys that attempt to structure survey questions to quantitatively inform preferences and model parameters in meaningful ways (Barsky, Juster, Kimball and Shapiro, 1997, Ameriks, Caplin, Laufer and van Nieuwerburgh, 2011, Brown, Goda and McGarry, 2015, Fuster and Zafar, 2016, Ameriks, Briggs, Caplin, Shapiro and Tonetti, 2017, 2018, Wiswall and Zafar, 2017, among others). Second, we relate to a number of studies that attempt to use surveys to measure retirement plans (Hurd, 2009) or factors that affect late-in-life labor supply decisions, including but not limited to the age composition of coworkers (Blau and Shvydko, 2011), career attachment and job satisfaction (Gobeski and Beehr, 2009), pension and hours arrangements (van Soest, Kapteyn and Zissimopoulos, 2007, van Soest and Vonkova, 2014, Kantarci and van Soest, 2015), and disability (Kapteyn, Smith and van Soest, 2008). Our study differs, however, due to the level of detail we include in our hypothetical scenarios and the resulting quantitative measures that this approach delivers which can be directly used to estimate parameters in retirement models. The survey approach used in this paper also complements the literature on revealed preference for work arrangements from experiments (Bloom, Liang, Roberts, and Ying, 2015, Mas and Pallais, 2017a, 2017b, among others) and behavioral data on workers' choices (Chen, Chevalier, Rossi and Oehlsen, 2017, Sorkin, 2018, among others). 


\section{Conclusion}

By combining new behavioral data on late-in-life employment and job-search activity with hypothetical SSQs, we find a strong and prevalent willingness to work among older Americans. At the time of the survey, many individuals, even those years removed from their last job, would like to return to work if they found a job similar to the last job they held. Individuals also expressed a willingness to continue working at the time of retirement. The willingness to work is stronger when jobs offer a flexible choice of hours worked. Individuals are willing to take substantial earnings reductions to gain hour flexibility. From these findings we conclude that labor force participation near and after normal retirement ages is limited more by a lack of acceptable job opportunities or low expectations about finding them, in particular jobs with part-time or flexible schedules, than by unwillingness to work longer. Given that the sample used in this paper tend to be healthier, wealthier, and more educated than the population of older Americans, and also that they had occupations that do not much require physical strength, limits from the demand side might be more prevalent for the general older population. Thus, demand-side factors (e.g., a nonconvexity in production that discourages part-time hires) are likely to be important in explaining current late-in-life labor market behavior and need to be considered in designing policies aiming to promote working longer. Our results suggest that any policies that induce firms to provide jobs with a flexible schedule to older Americans, even at a wage lower than what they used to have, will bring many back to the labor market. On the other hand, what policies would induce firms to do so and whether those policies would be welfare-improving depend on whether and why firms are less willing to hire older workers, in particular on a part-time basis. Hence, the findings from this paper call for further research on these demand side issues (see Goldin and Katz, 2011, Neumark, Burn and Button, 2016, and Burtless, 2017 as examples of recent work).

\section{References}

[1] Aaronson, Daniel and Eric French (2004): "The Effect of Part-Time Work on Wages: Evidence from the Social Security Rules," Journal of Labor Economics, 22, 329-352.

[2] Ameriks, John, Joseph Briggs, Andrew Caplin, Matthew D. Shapiro, and Christopher Tonetti (2017): "Long-Term-Care Utility and Late-in-Life Saving," Vanguard Research Initiative Working Paper.

[3] Ameriks, John, Joseph Briggs, Andrew Caplin, Matthew D. Shapiro, and Christopher Tonetti (2018): "The Long-Term-Care Insurance Puzzle: Modeling and Measurement," Vanguard Research Initiative Working Paper.

[4] Ameriks, John, Andrew Caplin, Steven Laufer, and Stijn van Nieuwerburgh (2011): "The Joy of Giving or Assisted Living? Using Strategic Surveys to Separate Public Care Aversion from Bequest Motives," Journal of Finance, 66, 519-561.

[5] Ameriks, John, Andrew Caplin, Minjoon Lee, Matthew D. Shapiro, and Christopher Tonetti (2014): "The Wealth of Wealthholders," Vanguard Research Initiative Working Paper. 
[6] Attanasio, Orazio, Sagiri Kitao, and Giovanni L. Violante (2007): "Global Demographic Trends and Social Security Reform," Journal of Monetary Economics, 54, 144-198.

[7] Barsky, Robert B., F. Thomas Juster, Miles S. Kimball, and Matthew D. Shapiro (1997): "Preference Parameters and Behavioral Heterogeneity: An Experimental Approach in the Health and Retirement Studies," Quarterly Journal of Economics, 112, 537-579.

[8] Berkovec, James and Steven Stern (1991): “Job Exit Behavior of Older Men," Econometrica, 59, 189-210.

[9] Blau, David M. and Donna B. Gilleskie (2008): "The Role of Retiree Health Insurance in the Employment Behavior of Older Men," International Economic Review, 49, 475-514.

[10] Blau, David M. and Tetyana Shvydko (2011): "Labor Market Rigidities and the Employment Behavior of Older Workers," Industrial and Labor Relations Review, 64, 464-484.

[11] Blondal, Sveinbjorn and Stefano Scarpetta (1999): "The Retirement Decision in OECD Countries," OECD Economics Department Working Papers No. 202.

[12] Bloom, Nicholas, James Liang, John Roberts, and Zhichun Jenny Ying (2015): "Does Working from Home Work? Evidence from a Chinese Experiment," Quarterly Journal of Economics, 130, $165-218$.

[13] Blundell, Richard, Costas Meghir, and Sarah Smith (2002): "Pension Incentives and the Pattern of Early Retirement," Economic Journal, 112, C153-C170.

[14] Brown, Jeffrey R., Gopi Shah Goda, and Kathleen McGarry (2016): "Heterogeneity in StateDependent Utility: Evidence from Strategic Surveys," Economic Inquiry, 54, 847-861.

[15] Burtless, Gary (2017): "Age Related Health Costs and Job Prospects of Older Workers," Paper presented at the SIEPR Working Longer and Retirement Conference.

[16] Cahill, Kevin E., Michael D. Giandrea, and Joseph F. Quinn (2006): "Retirement Patterns from Career Employment," The Gerontologist, 46, 514-523.

[17] Casanova, Maria (2013): "Revisiting the Hump-Shaped Wage Profile," Mimeo.

[18] Chan, Sewin and Ann Huff Stevens (2001): "Job Loss and Employment Patterns of Older Workers," Journal of Labor Economics, 19, 484-521.

[19] Chen, M. Keith, Judith A. Chevalier, Peter E. Rossi, and Emily Oehlsen (2017): "The Value of Flexible Work: Evidence from Uber Drivers," NBER Working Paper, No. 23296.

[20] Chetty, Raj (2012): "Bounds on Elasticities with Optimization Frictions: A Synthesis of Micro and Macro Evidence on Labor Supply," Econometrics, 80, 969-1018.

[21] De Nardi, Mariacristina, Selahattin Imrohoroglu, and Thomas Sargent (1999): "Projected U.S. Demographics and Social Security," Review of Economic Dynamics, 2, 575-615. 
[22] Domeij, David and Martin Floden (2006): "The Labor-Supply Elasticity and Borrowing Constraint: Why Estimates are Biased," Review of Economic Dynamics, 9, 242-262.

[23] Duval, Romain (2003): "The Retirement Effects of Old-Age Pension and Early Retirement Schemes in OECD Countries," OECD Economics Department Working Papers No. 370.

[24] Ermisch, John and Robert Wright (1993): "Wage Offers and Full-Time and Part-Time Employment by British Women," Journal of Human Resources, 28, 111-133.

[25] Euwals, Rob, Annemiek van Vuren, and Daniel van Vuuren (2012): "The Decline of Substitute Pathways into Retirement: Empirical Evidence from the Dutch Health Care Sector," International Social Security Review, 65, 101-122.

[26] Faberman, R. Jason, Andreas I. Mueller, Aysegul Sahin, and Giorgio Topa (1984): "Job Search Behavior among the Employed and Non-Employed," NBER Working Paper No. 23731.

[27] Feldstein, Martin and James Poterba (1984): "Unemployment Insurance and Reservation Wages," Journal of Public Economics, 23, 141-167.

[28] French, Eric (2005): "The Effects of Health, Wealth, and Wages on Labour Supply and Retirement Behavior," Review of Economic Studies, 72, 395-427.

[29] French, Eric and John Bailey Jones (2011): "The Effects of Health Insurance and Self-Insurance on Retirement Behavior," Econometrica, 79, 693-732.

[30] Fuchs, Victor R. (1984): "Though Much is Taken: Reflections on Aging, Health, and Medical Care," NBER Working Paper No. 1269.

[31] Fuster, Andreas and Basit Zafar (2016): "To Buy or Not To Buy: Consumer Constraints in the Housing Market," American Economic Review, 106, 636-640.

[32] Gobeski, Kirsten T. and Terry A. Beehr (2009): "How Retirees Work: Predictors of Different Types of Bridge Employment," Journal of Organizational Behavior, 30, 401-425.

[33] Goldin, Claudia and Lawrence F. Katz (2011): "The Cost of Workplace Flexibility for HighPowered Professionals," Annals of American Academy of Political and Social Science, 638, 45-67.

[34] Gustman, Alan L. and Thomas L. Steinmeier (1986): "A Structural Retirement Model," Econometrica, 54, 555-584.

[35] Gustman, Alan L. and Thomas L. Steinmeier, and Nahid Tabatabai (2016): "The Affordable Care Act as Retiree Health Insurance: Implications for Retirement and Social Security Claiming," NBER Working Paper No. 22815.

[36] Gruber, Jonathan and David Wise (1998): "Social Security and Retirement: An International Comparison," American Economic Review, 88, 158-163. 
[37] Gruber, Jonathan and David Wise (1999): "Social Security, Retirement Incentives, and Retirement Behavior: An International Perspective," EBRI Issue Brief, 209, 1-22.

[38] Gruber, Jonathan and David Wise (2002): "Social Security Programs and Retirement around the World," Research in Labor Economics, 18, 1-40.

[39] Gruber, Jonathan and David Wise (2007): "Introduction" to Jonathan Gruber and David Wise eds., Social Security Programs and Retirement around the World: Fiscal Implications of Reform, University of Chicago Press.

[40] Heckman, James J., Lance Lochner and Christopher Taber (1998): "Explaining Rising Wage Inequality: Explorations with a Dynamic General Equilibrium Model of Labor Earnings with Heterogeneous Agents," Review of Economic Dynamics, 1, 1-58.

[41] Huggett, Mark, Gustavo Ventura and Amir Yaron (2011): "Sources of Lifetime Inequality," American Economic Review, 101, 2923-2954.

[42] Holzer, Harry J. (1986): "Reservation Wages and Their Labor Market Effects for Black and White Male Youth," Journal of Human Resources, 21, 157-177.

[43] Hurd, Michael D. (1996): "The Effect of Labor Market Rigidities on the Labor Force Behavior of Older Workers" in David Wise ed., Advances in the Economics of Aging, University of Chicago Press.

[44] Hurd, Michael D. (2009): "Subjective Probabilities in Household Surveys," Annual Review of Economics, 1, 543-562.

[45] Jacobs, Lindsay and Suphanit Piyapromdee (2016): "Labor Force Transitions at Older Ages: Burnout, Recovery, and Reverse Retirement," Board of Governors of the Federal Reserve System Finance and Economics Discussion Series No. 2016-053.

[46] Johnson, Richard (2001): "The Effect of Old-Age Insurance on Male Retirement: Evidence from Historical Cross-Country Data," FRB of Kansas City Research Working Paper No. 00-09.

[47] Kantarci, Tunga and Arthur van Soest (2008): "Gradual Retirement: Preferences and Limitations," De Economist, 156, 113-144.

[48] Kantarci, Tunga and Arthur van Soest (2015): "Full or Partial Retirement? Effects of the Pension Incentives and Increasing Retirement Age in the Netherlands and the United States," Netspar Discussion Paper No. 2013-038.

[49] Kapteyn, Arie, James P. Smith and Arthur van Soest (2008): "Dynamics of Work Disability and Pain," Journal of Health Economics, 27, 496-509.

[50] Keane, Michael P. (2011): "Labor Supply and Taxes: A Survey," Journal of Economic Literature, 49, 961-1075. 
[51] Kotlikoff, Laurence J., Kent Smetters, and Jan Walliser (2002): "Distributional Effects in a General Equilibrium Analysis of Social Security" in Martin S. Feldstein and Jeffrey B. Liebman eds., The Distributional Aspects of Social Security and Social Security Reform, University of Chicago Press, 327-361.

[52] Krueger, Alan B. and Andreas I. Mueller (2016): "A Contribution to the Empirics of Reservation Wages," American Economic Journal: Economic Policy, 8, 142-179.

[53] Lee, Ronald and Jonathan Skinner (1999): "Will Aging Baby Boomers Bust the Federal Budget?" Journal of Economic Perspectives, 13, 117-140.

[54] Madrian, Brigitte C., Gary Burtless, and Jonathan Gruber (1994): "The Effect of Health Insurance on Retirement," Brookings Papers on Economic Activity, 1994 (1), 181-252.

[55] Maestas, Nicole (2010): "Back to Work: Expectations and Realizations of Work after Retirement," Journal of Human Resources, 45, 718-748.

[56] Maestas, Nicole and Xiaoyan Li (2007): "Burnout and the Retirement Decision," Michigan Retirement Research Center Research Paper No. 2007-166.

[57] Mas, Alexandre and Amanda Pallais (2017a): "Valuing Alternative Work Arrangements," American Economic Review, 107, 3722-59.

[58] Mas, Alexandre and Amanda Pallais (2017b): "Labor Supply and the Value of Non-Work Time: Experimental Estimates from the Field," NBER Working Paper, No. 23906.

[59] Moffitt, Robert (1984): "The Estimation of a Joint Wages-Hours Labor Supply Model," Journal of Labor Economics, 2, 550-566.

[60] Neumark, David, Ian Burn, and Patrick Button (2016): "Experimental Age Discrimination Evidence and the Heckman Critique," American Economic Review, 106, 303-308.

[61] OECD (2006): "Live Longer, Work Longer," OECD report.

[62] Pistaferri, Luigi (2003): "Anticipated and Unanticipated Wage Changes, Wage Risk, and Intertemporal Labor Supply," Journal of Labor Economics, 21, 729-754.

[63] Ramnath, Shanthi, John B. Shoven, and Sita Nataraj Slavov (2017): "Pathways to Retirement through Self-Employment," NBER Working Paper No. 23551.

[64] Rogerson, Richard and Johanna Wallenius (2013): "Nonconvexities, Retirement, and the Elasticity of Labor Supply," American Economic Review, 103, 1445-1462.

[65] Rosen, Harvey (1976): "Taxes in a Labor Supply Model with Joint Wages-Hours Determination," Econometrica, 44, 485-507.

[66] Ruhm, Christopher J. (1990): "Bridge Jobs and Partial Retirement," Journal of Labor Economics, 8, 482-501. 
[67] Rupert, Peter and Giulio Zanella (2015): "Revisiting Wage, Earnings, and Hours Profiles," Journal of Monetary Economics, 72, 114-130.

[68] Rust, John and Christopher Phelan (1997): "How Social Security and Medicare Affect Retirement Behavior in a World of Incomplete Markets," Econometrica, 65, 781-831.

[69] Scott, John C. (2004): "Is Phased Retirement a State of Mind? The Role of Individual Preferences in Retirement Outcomes," Paper presented at the Annual Meeting of the Population Association of America.

[70] Shimer, Robert. (2010): Labor Markets and Business Cycles, Princeton University Press.

[71] Trabandt, Mathias and Harald Uhlig (2009): "How Far are We from the Slippery Slope? The Laffer Curve Revisited," NBER Working Paper, 15343.

[72] van der Klauuw, Wilbert and Kenneth I. Wolpin (2008): "Social Security and the Retirement and Savings Behavior of Low-Income Households," Journal of Econometrics, 145, 21-42.

[73] van Soest, Authur, Arie Kapteyn and Julie M. Zissimopoulos (2007): "Using Stated Preferences Data to Analyze Preference for Full and Partial Retirement," RAND Working Paper Series No. WR-345.

[74] van Soest, Authur and Hana Vonkova (2014): "How Sensitive are Retirement Decisions to Financial Incentives? A Stated Preference Analysis," Journal of Applied Econometrics, 29, 246-264.

[75] Sorkin, Isaac (2018): "Ranking Firms Using Revealed Preference," Quarterly Journal of Economics, forthcoming.

[76] Wiswall, Matthew J. and Basit Zafar (2017): "Preference for the Workplace, Investment in Human Capital, and Gender," Quarterly Journal of Economics, forthcoming. 


\section{A Appendix: VRI Sample Characteristics and Comparison with HRS Sample}

This Appendix compares the VRI sample used in this paper, i.e., those who completed Survey 4, with the HRS sample from the 2012 wave, focusing on job characteristics. (See Ameriks, Caplin, Lee, Shapiro and Tonetti, 2014, for the more detailed comparisons using the entire VRI sample.) We consider the HRS sample who are at least 55 years old to match the age eligibility for the VRI sample ("age-eligible" sample). To account for the effects of the additional sampling screens used in the VRI, that the respondents need to have at least $\$ 10,000$ in their Vanguard accounts and be internet eligible, we also consider the subset of the age-eligible HRS sample who have at least $\$ 10,000$ in non-transactional accounts and have internet access ("VRI-eligible" sample).

Table A.1 presents selected sample characteristics for the VRI sample including age, financial wealth, marital status, and education levels. Ages are distributed approximately equally in age bins $55-59,60-64,65-69,70-74$, and $75+$, the median household has about $\$ 800,000$ of financial wealth, $67 \%$ have a partner, $34 \%$ are female, $76 \%$ have a college degree or higher, and $95 \%$ report having good health or better. Table A.2 summarizes the distribution of corresponding variables in the HRS sample. The VRI sample tends to be wealthier, more educated, more likely to be married and healthier, though

a large part of this gap is explained by the screens imposed in the VRI sampling. After adjusting for sampling weights, $41 \%$ of the HRS sample satisfy the VRI sampling screens. Employment status patterns are also similar between the VRI (Table 1) and HRS (Table A.3), though the fraction of those working in a bridge job is higher in the HRS.

In terms of the characteristics of the career job (defined as the job with the longest tenure for the HRS sample), the age-eligible HRS sample (Table A.4) has similar length of tenure, similar working hours, and lower salary than the VRI sample (Table 2). The gap in the salary is smaller for the VRIeligible HRS sample (Table A.5). The most common industries and occupations of the age-eligibile HRS sample also largely overlap with those from the VRI sample. Overall, these comparisons confirm that once the sampling screens for the VRI are imposed on the HRS sample, the two samples have similar job characteristics. 
Table A.1: VRI respondent characteristics

\begin{tabular}{|c|c|c|c|c|c|c|}
\hline \multirow{10}{*}{$\begin{array}{l}\text { Age: } \\
\text { Financial wealth: }\end{array}$} & \multicolumn{6}{|c|}{ Age and Wealth } \\
\hline & $10 p$ & $25 p$ & $50 p$ & $75 \mathrm{p}$ & $90 p$ & Mean \\
\hline & 60 & 64 & 69 & 75 & 79 & 70 \\
\hline & 172,665 & 394,041 & 821,252 & $1,495,714$ & $2,621,855$ & $1,248,491$ \\
\hline & \multicolumn{2}{|c|}{ Married } & & \multicolumn{3}{|c|}{ Education } \\
\hline & Yes & No & & $\leq$ College & College & $>$ College \\
\hline & $67 \%$ & $33 \%$ & & $24 \%$ & $32 \%$ & $44 \%$ \\
\hline & \multicolumn{2}{|c|}{ Sex } & & \multicolumn{3}{|c|}{ Health } \\
\hline & $\underline{\text { Female }}$ & Male & & $\begin{array}{l}\text { Excellent/ } \\
\text { Very Good }\end{array}$ & Good & $\begin{array}{l}\text { Fair/ } \\
\text { Poor }\end{array}$ \\
\hline & $34 \%$ & $66 \%$ & & $73 \%$ & $22 \%$ & $\overline{5 \%}$ \\
\hline
\end{tabular}

Notes: Survey 4 respondents. N=2,772. Financial wealth is from Survey 1 and adjusted to $2015 \$$. 
Table A.2: The HRS sample characteristics

\begin{tabular}{|c|c|c|c|c|c|c|}
\hline \multirow[t]{2}{*}{ A. Age eligible } & \multicolumn{6}{|c|}{ Age and Wealth } \\
\hline & $10 p$ & $25 p$ & $50 p$ & $75 \mathrm{p}$ & $90 p$ & Mean \\
\hline Age: & $\overline{56}$ & $\overline{60}$ & $\overline{66}$ & $\overline{75}$ & $\overline{83}$ & 68 \\
\hline \multirow[t]{6}{*}{ Financial wealth: } & $-7,716$ & 0 & 40,126 & 257,826 & 718,126 & 264,974 \\
\hline & \multicolumn{2}{|c|}{ Married } & & \multicolumn{3}{|c|}{ Education } \\
\hline & $\underline{\text { Yes }}$ & $\underline{\text { No }}$ & & $<$ College & College & $>$ College \\
\hline & $50 \%$ & $50 \%$ & & $72 \%$ & $13 \%$ & $15 \%$ \\
\hline & \multicolumn{2}{|c|}{ Sex } & & \multicolumn{3}{|c|}{ Health } \\
\hline & $\frac{\text { Female }}{52 \%}$ & $\frac{\text { Male }}{48 \%}$ & & $\begin{array}{c}\text { Excellent/ } \\
\text { Very Good } \\
42 \%\end{array}$ & $\frac{\text { Good }}{32 \%}$ & $\begin{array}{l}\text { Fair/ } \\
\frac{\text { Poor }}{26 \%}\end{array}$ \\
\hline
\end{tabular}

B. VRI eligible

\begin{tabular}{lcc} 
Age: & $\frac{\mathbf{1 0 p}}{56}$ & $\frac{\mathbf{2 5 p}}{59}$ \\
Financial wealth: & 21,657 & 78,706 \\
& Married \\
\cline { 2 - 3 } & $\frac{\text { Yes }}{67 \%}$ & $\frac{\mathbf{N o}}{33 \%}$ \\
& \multicolumn{2}{c}{ Sex } \\
\hline
\end{tabular}

Age and Wealth

$\begin{array}{cccc}\frac{\mathbf{5 0 p}}{63} & \frac{\mathbf{7 5 p}}{70} & \frac{\mathbf{9 0 p}}{77} & \frac{\text { Mean }}{65} \\ 40,233 & 599,810 & 1,229,457 & 537,920\end{array}$

Education

\begin{tabular}{cc}
$\frac{<\text { College }}{51 \%}$ & $\frac{\text { College }}{22 \%} \quad \frac{\text { College }}{27 \%}$ \\
& Health \\
\hline
\end{tabular}

\begin{tabular}{|c|c|}
\hline $\begin{array}{l}\text { Excellent/ } \\
\text { Very Good }\end{array}$ & Good \\
\hline $58 \%$ & $29 \%$ \\
\hline
\end{tabular}

Notes: The first panel uses all the "financial respondents" (the respondents who answered questions regarding household finance in case there are multiple respondents in one household) who are age 55 or above $(\mathrm{N}=11,741)$. For the second panel we impose additional criteria that respondents are internet eligible and have at least $\$ 10,000$ in non-transactional accounts $(\mathrm{N}=3,800)$. All tabulations are weighted using HRS sampling weights. Financial wealth is in $2015 \$$. 
Table A.3: Employment status: the HRS sample

\begin{tabular}{|c|c|c|c|c|c|c|}
\hline \multirow[b]{3}{*}{ A. Age eligible } & \multicolumn{5}{|c|}{ By Age } & \multirow[t]{3}{*}{ Total } \\
\hline & $\underline{55-59}$ & $\underline{60-64}$ & $\underline{65-69}$ & $\underline{70-74}$ & $\underline{75-}$ & \\
\hline & & & & & & \\
\hline Employed (\%) & 73.6 & 57.9 & 39.7 & 29.2 & 14.9 & 43.7 \\
\hline In a career job $(\%)$ & 41.1 & 26.8 & 14.9 & 8.5 & 2.8 & 19.6 \\
\hline In a bridge job (\%) & 32.5 & 31.1 & 24.8 & 20.7 & 12.1 & 24.1 \\
\hline Not employed (\%) & 26.4 & 42.2 & 60.3 & 70.8 & 85.2 & 56.3 \\
\hline Retired (\%) & 18.0 & 39.2 & 58.9 & 69.9 & 84.1 & 53.0 \\
\hline Not retired (\%) & 8.4 & 3.0 & 1.4 & 0.9 & 1.1 & 3.3 \\
\hline $\mathbf{N}$ & 2,433 & 2,037 & 1,291 & 1,991 & 3,989 & 11,741 \\
\hline \multicolumn{7}{|l|}{ B. VRI eligible } \\
\hline Employed (\%) & 84.5 & 69.6 & 47.0 & 36.2 & 18.0 & 58.4 \\
\hline In a career job $(\%)$ & 50.0 & 32.2 & 18.3 & 10.4 & 4.4 & 28.3 \\
\hline In a bridge job (\%) & 34.5 & 37.4 & 28.7 & 25.8 & 13.6 & 30.1 \\
\hline Not employed (\%) & 15.5 & 30.5 & 53.0 & 63.8 & 82.1 & 41.5 \\
\hline Retired (\%) & 11.8 & 29.2 & 52.4 & 63.2 & 81.9 & 39.9 \\
\hline Not retired (\%) & 3.7 & 1.3 & 0.6 & 0.6 & 0.2 & 1.6 \\
\hline $\mathbf{N}$ & 973 & 763 & 555 & 669 & 840 & 3,800 \\
\hline
\end{tabular}

Notes: See the notes for Table A.2. 
Table A.4: Career Job Characteristics: Age-Eligible HRS

\begin{tabular}{|c|c|c|c|c|c|c|}
\hline \multirow[t]{2}{*}{ A. Retired from career job } & \multicolumn{6}{|c|}{ Years worked } \\
\hline & $10 p$ & $25 p$ & $50 p$ & $75 p$ & $90 p$ & $\underline{\text { Mean }}$ \\
\hline Years worked: & 6 & 10 & 18 & 28 & 34 & 19 \\
\hline \multirow[t]{3}{*}{ Most common industries: } & \multicolumn{5}{|c|}{ Manufacturing } & $17.3 \%$ \\
\hline & \multicolumn{5}{|c|}{ Health care and social assist } & $11.0 \%$ \\
\hline & \multicolumn{5}{|c|}{ Retail trade } & $8.6 \%$ \\
\hline \multirow{3}{*}{ Most common occupations: } & \multicolumn{5}{|c|}{ Office and admin support } & $13.1 \%$ \\
\hline & \multicolumn{5}{|c|}{ Sales and related } & $11.2 \%$ \\
\hline & \multicolumn{5}{|c|}{ Management } & $11.1 \%$ \\
\hline
\end{tabular}

\begin{tabular}{|c|c|c|c|c|c|c|}
\hline \multirow[t]{2}{*}{ B. Working on career job } & \multicolumn{6}{|c|}{ Years worked, salary, hours worked } \\
\hline & $10 p$ & $25 p$ & $50 p$ & $75 \mathrm{p}$ & $90 p$ & Mean \\
\hline Years worked: & 7 & 13 & 21 & 32 & 37 & 22 \\
\hline Salary (in 2015\$): & 13,716 & 27,820 & 50,557 & 80,249 & 119,345 & 68,367 \\
\hline Hours worked (per year): & 1,000 & 1,800 & 2,080 & 2,340 & 2,750 & 2,015 \\
\hline \multirow[t]{2}{*}{ Self-employed: } & \multicolumn{5}{|l|}{ Yes } & $24.3 \%$ \\
\hline & \multicolumn{5}{|l|}{ No } & $75.7 \%$ \\
\hline \multirow[t]{3}{*}{ Most common industries: } & \multicolumn{5}{|c|}{ Health care and social assist } & $14.9 \%$ \\
\hline & \multicolumn{5}{|c|}{ Manufacturing } & $11.2 \%$ \\
\hline & \multicolumn{5}{|c|}{ Professional, scientific, tech. services } & $11.2 \%$ \\
\hline \multirow[t]{3}{*}{ Most common occupations: } & \multicolumn{5}{|c|}{ Management } & $14.4 \%$ \\
\hline & \multicolumn{5}{|c|}{ Sales and related } & $11.7 \%$ \\
\hline & \multicolumn{5}{|c|}{ Office and administrative support } & $9.4 \%$ \\
\hline
\end{tabular}

Notes: Career job is defined as the job with the longest tenure. This table uses all the financial respondents who are age 55 or above and reported the tenure on their longest job $(\mathrm{N}=8,940$ for Panel $\mathrm{A}$ and $\mathrm{N}=1,891$ for Panel B). 
Table A.5: Career Job Characteristics: VRI-Eligible HRS

A. Retired from career job Years worked

Years worked:

\begin{tabular}{llllll} 
Years worked \\
\hline$\frac{\mathbf{1 0 p}}{8}$ & $\frac{\mathbf{2 5 p}}{12}$ & $\frac{\mathbf{5 0 p}}{20}$ & $\frac{\mathbf{7 5} \mathbf{p}}{29}$ & $\frac{\mathbf{9 0 p}}{35}$ & $\frac{\text { Mean }}{21}$
\end{tabular}

Most common industries:

Manufacturing

$18.7 \%$

Health care and social assist

$11.8 \%$

Educational services

$8.1 \%$

Most common occupations: Management

$18.5 \%$

Office and admin support

$14.6 \%$

Sales and related

$12.9 \%$

B. Working on career job

Years worked, salary, hours worked

Years worked:

Salary (in 2015\$):

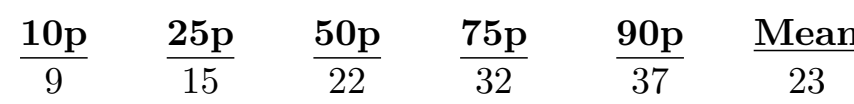

Self-employed:

Yes

$24.1 \%$

No

$75.9 \%$

Most common industries: Professional, scientific, tech. services

$14.4 \%$

Health care and social assist

$13.7 \%$

Manufacturing

$12.1 \%$

Most common occupations: Management

$18.3 \%$

Sales and related

$11.5 \%$

Business and financial operation

$10.5 \%$

Notes: Career job is defined as the job with the longest tenure. This table uses all the financial respondents who are VRI-eligible and reported the tenure on their longest job $(\mathrm{N}=2,890$ for Panel A and $\mathrm{N}=910$ for Panel B). 


\section{B Appendix: Additional Results from Behavioral Data}

\section{B.1 Career Job Characteristics: Workers, by Age Group}

Table B.1 tabulates career job characteristics, among those who are still working on their career jobs, for three different age groups: not older than 62, between 63 and 65, and older than 65. The share of workers who are self-employed or have a flexible schedule increases with age, in particular after 65 . Only $9 \%$ of workers were self-employed before age 63 while $34 \%$ of those older than 65 are selfemployed. The share having a flexible schedule changes from $36 \%$ to $71 \%$ between these two age groups. This finding suggests that it is primarily the selection effect that makes these characteristics more common among those who are still on their career jobs compared to those who have separated from their career job. This, in turn, suggests that these characteristics are preferred by older workers and hence encourage them to work longer, consistent with the findings by Ramnath, Shoven, and Slavov (2017).

There are other patterns that are notable. The number of hours worked decreases significantly, in particular in the left tail, after age 65. This suggests again that flexibility in the work schedule is more valued in late life. Being able to reduce the work burden at the beginning of the pathway to retirement seems to be appreciated by older workers. There is no noticeable change in hourly wage. This might be a result of two competing forces: older workers being less productive putting downward pressure on measured earnings and workers with higher wages selecting into working longer putting upward pressure on measured earnings. Note also that the share of jobs with health insurance provision drops significantly at age 65. This may reflect older workers becoming eligible for Medicare at this age.

There are also changes in the distribution of industries and occupations across the age groups. Those working in the manufacturing or transportation and warehousing industries are less likely to stay longer while those who work in professional, scientific, and technical services or educational services are more likely to stay longer. Those who have management positions tend to stay shorter while those who have education-related occupations tend to stay longer.

These findings hint at the job characteristics that encourage workers to stay in their career jobs, even after the normal retirement ages. Having control over their own work schedules (either through self-employment or by having a flexible schedule) seems to be an important factor, and being able to reduce the work burden at the beginning of the pathway to retirement turns out to be a key reason workers want flexible hours.

\section{B.2 Career to Bridge Job Transition and Gaining Flexibility in Work Schedule}

In this appendix we provide a more detailed decomposition of the share of bridge jobs with flexible schedules. In particular, we investigate how much of the increase in the share of jobs with flexible schedules from career jobs to bridge jobs is driven by transitions into an industry or occupation where having a flexible schedule is more common and how much is due to an increase in the share of flexible jobs within each industry or occupation. In Table B.2, we list the common industries and occupations for the sample who ever had a bridge job, along with the share of career and bridge jobs in each category (second and third columns) and the share of jobs with flexible schedules among the jobs in 
Table B.1: Career Job Characteristics: Workers, by Age Group

\begin{tabular}{|c|c|c|c|c|c|c|}
\hline \multirow[t]{2}{*}{ A. Age $\leq 62$} & \multicolumn{6}{|c|}{ Salary, hours worked, hourly wage } \\
\hline & 10p & $25 p$ & $50 p$ & $75 \mathrm{p}$ & $90 p$ & Mean \\
\hline Salary (in 2015\$): & $3 \overline{0,000}$ & $5 \overline{7,000}$ & $8 \overline{5,000}$ & $1 \overline{23,782}$ & $1 \overline{77,964}$ & 101,169 \\
\hline Hours worked (per year): & 1,440 & 2,080 & 2,080 & 2,340 & 2,600 & 2,062 \\
\hline Hourly wage (in $2015 \$$ ): & 19 & 28 & 40 & 58 & 85 & 51 \\
\hline \multirow[t]{2}{*}{ Self-employed: } & Yes & & & & & $8.8 \%$ \\
\hline & No & & & & & $91.2 \%$ \\
\hline \multirow[t]{2}{*}{ Had a flexible schedule: } & Yes & & & & & $36.3 \%$ \\
\hline & No & & & & & $63.7 \%$ \\
\hline \multirow[t]{2}{*}{ Health insurance provision: } & Yes & & & & & $83.0 \%$ \\
\hline & No & & & & & $17.0 \%$ \\
\hline \multirow[t]{2}{*}{ B. Age 63-65 } & \multicolumn{6}{|c|}{ Salary, hours worked, hourly wage } \\
\hline & 10p & $25 p$ & $50 p$ & $75 \mathrm{p}$ & $90 p$ & Mean \\
\hline Salary (in 2015\$): & $3 \overline{2,000}$ & $5 \overline{2,000}$ & $8 \overline{5,000}$ & $1 \overline{20,917}$ & $2 \overline{200,000}$ & $\overline{107,770}$ \\
\hline Hours worked (per year): & 884 & 1820 & 2,080 & 2,250 & 2,600 & 1,944 \\
\hline Hourly wage (in 2015\$): & 19 & 28 & 42 & 58 & 120 & 62 \\
\hline \multirow[t]{2}{*}{ Self-employed: } & Yes & & & & & $11.0 \%$ \\
\hline & No & & & & & $89.0 \%$ \\
\hline \multirow[t]{2}{*}{ Had a flexible schedule: } & Yes & & & & & $50.9 \%$ \\
\hline & No & & & & & $49.1 \%$ \\
\hline \multirow[t]{2}{*}{ Health insurance provision: } & Yes & & & & & $85.4 \%$ \\
\hline & No & & & & & $14.6 \%$ \\
\hline \multirow[t]{2}{*}{ C. Age $\geq 66$} & \multicolumn{6}{|c|}{ Salary, hours worked, hourly wage } \\
\hline & $\underline{10 p}$ & $25 \mathrm{p}$ & $50 \mathrm{p}$ & $75 \mathrm{p}$ & $90 p$ & Mean \\
\hline Salary (in $2015 \$$ ): & $\overline{3,500}$ & $1 \overline{5,500}$ & $5 \overline{0,000}$ & $9 \overline{4,000}$ & $1 \overline{55,000}$ & 64,202 \\
\hline Hours worked (per year): & 156 & 480 & 1,540 & 2,080 & 2,160 & 1,337 \\
\hline Hourly wage (in 2015\$): & 14 & 23 & 44 & 64 & 99 & 61 \\
\hline \multirow[t]{2}{*}{ Self-employed: } & Yes & & & & & $33.7 \%$ \\
\hline & No & & & & & $66.3 \%$ \\
\hline \multirow[t]{2}{*}{ Had a flexible schedule: } & Yes & & & & & $71.2 \%$ \\
\hline & No & & & & & $28.8 \%$ \\
\hline \multirow[t]{2}{*}{ Health insurance provision: } & Yes & & & & & $39.2 \%$ \\
\hline & No & & & & & $60.8 \%$ \\
\hline
\end{tabular}

Notes: $\mathrm{N}=321$ for group $\mathrm{A}, \mathrm{N}=117$ for group $\mathrm{B}$, and $\mathrm{N}=163$ for group $\mathrm{C}$. 
Table B.1: Career Job Characteristics: Workers, by Age Group (Continued)

\begin{tabular}{|c|c|c|c|}
\hline \multirow[t]{2}{*}{ D. Share of selected industries } & \multicolumn{3}{|c|}{ Age group } \\
\hline & $\leq 62$ & $\underline{63-65}$ & $\geq 66$ \\
\hline Professional, scientific, and technical services & $17.7 \%$ & $17.1 \%$ & $21.5 \%$ \\
\hline Manufacturing & $12.8 \%$ & $12.0 \%$ & $5.5 \%$ \\
\hline Transportation and Warehousing & $11.8 \%$ & $8.6 \%$ & $3.1 \%$ \\
\hline Health Care and Social Assistance & $6.2 \%$ & $12.8 \%$ & $8.6 \%$ \\
\hline Educational Services & $7.5 \%$ & $6.8 \%$ & $12.9 \%$ \\
\hline \multirow[t]{2}{*}{ E. Share of selected occupations } & \multicolumn{3}{|c|}{ Age group } \\
\hline & $\leq 62$ & $\underline{63-65}$ & $\geq 66$ \\
\hline Management & $2 \overline{1.5 \%}$ & $\overline{22.2 \%}$ & $12.3 \%$ \\
\hline Business and financial operations & $9.4 \%$ & $12.8 \%$ & $14.1 \%$ \\
\hline Computer and mathematical & $9.0 \%$ & $6.8 \%$ & $10.4 \%$ \\
\hline Office and administrative support & $8.7 \%$ & $10.3 \%$ & $8.6 \%$ \\
\hline Education, training, library & $4.4 \%$ & $3.4 \%$ & $11.0 \%$ \\
\hline
\end{tabular}

Notes: $\mathrm{N}=321$ for group $\mathrm{A}, \mathrm{N}=117$ for group $\mathrm{B}$, and $\mathrm{N}=163$ for group $\mathrm{C}$.

each category (the last two columns). ${ }^{26}$

We find that increases in the share of flexible jobs in each sector dominates the effect of transitions to more flexible industries and occupations. The share of flexible jobs varies across industries and occupations and there is indeed a tendency to switch to industries and occupations that are more likely to offer a job with flexible schedule. For example, older workers tend to leave the manufacturing industry, which has the lowest share of flexible jobs, while educational services, other services, and retail trade, which have higher shares of flexible jobs, attract more workers in late life. The extent of such switches, however, turns out to be too small to explain the large increase in the share of flexible jobs among bridge jobs. On the other hand, there is an increase in the share of flexible jobs within each industry, and the size of that increase is comparable to the overall difference in the share of flexible jobs between the bridge and career jobs. The same pattern also holds for occupations. Hence we conclude the reason a greater fraction of bridge jobs offer flexible schedules is mainly because people move to jobs with more flexibility while staying within their industry or occupation and is not primarily due to transitions to more flexible industries and occupations.

\footnotetext{
${ }^{26}$ Among 20 industry categories and 23 occupation categories used in the survey, we present the most common 8 industries and occupations.
} 
Table B.2: Industry and Occupation: Prevalence and Flexibility

\begin{tabular}{|c|c|c|c|c|}
\hline \multirow[t]{2}{*}{ A: Industry } & \multicolumn{2}{|c|}{ Prevalence $(\%)^{*}$} & \multicolumn{2}{|c|}{$\begin{array}{c}\text { Share of } \\
\text { flexible jobs }(\%) * *\end{array}$} \\
\hline & Career & Bridge & Career & Bridge \\
\hline Professional, scientific, and technical services & 23.0 & $\overline{20.6}$ & 26.7 & 59.9 \\
\hline Manufacturing & 12.6 & 6.3 & 8.8 & 25.5 \\
\hline Educational services & 9.7 & 11.3 & 31.7 & 52.2 \\
\hline Finance and insurance & 9.4 & 9.6 & 17.1 & 51.3 \\
\hline Health care and social assistance & 8.6 & 9.1 & 45.7 & 59.5 \\
\hline Public administration & 8.1 & 7.0 & 15.2 & 31.6 \\
\hline Other services & 4.7 & 8.6 & 34.2 & 67.1 \\
\hline Retail trade & 3.1 & 5.5 & 32.0 & 62.2 \\
\hline \multirow[t]{2}{*}{ B: Occupation } & \multicolumn{2}{|c|}{ Prevalence $(\%)^{*}$} & \multicolumn{2}{|c|}{$\begin{array}{c}\text { Share of } \\
\text { flexible jobs }(\%)^{* *}\end{array}$} \\
\hline & Career & Bridge & Career & Bridge \\
\hline Management & 26.2 & 18.6 & 20.7 & 49.0 \\
\hline Business and financial operations & 11.1 & 12.7 & 23.3 & 63.1 \\
\hline Computer and mathematical & 8.9 & 8.3 & 20.8 & 47.8 \\
\hline Architecture and engineering & 8.5 & 6.7 & 17.4 & 51.9 \\
\hline Education, training, and library & 7.5 & 9.2 & 39.4 & 60.0 \\
\hline Office and administrative support & 6.9 & 9.1 & 14.3 & 37.8 \\
\hline Sales and related & 6.4 & 8.1 & 21.2 & 51.5 \\
\hline Healthcare practitioners and technical & 5.7 & 5.7 & 52.2 & 67.4 \\
\hline
\end{tabular}

Notes: * Prevalence is defined as the share of career and bridge jobs that are in each industry/occupation among the VRI sample who had a bridge job $(\mathrm{N}=812)$.

** This share is defined as the share of jobs with flexible schedule among the jobs in each industry/occupation in the entire VRI sample, separately for career and bridge jobs. 


\section{Appendix: Detailed SSQ Scenarios}

The SSQs asked in VRI Survey 4 vary in terms of job characteristics, timing of the job offer, and the sample that received the questions. Table C.1 provides the complete list of the SSQs asked. Considered alternative characteristics include allowing for a flexible schedule (respondents can choose the number of hours per year instead of having to work for the same number of hours as in the reference job) and allowing for an alternative occupation (the opportunity comes with an occupation that is different than the reference occupation and is the most preferred one by respondents). The SSQs also vary in terms of the timing of the offer (offer available at the time of the survey, SSQ1A, versus a retrospective offer assumed to have been available at the time of retirement, SSQ1B). They also vary in whether the offer is a new employment situation (SSQ1A, SSQ1B) or a continuation of the current employment situation (SSQ2). In SSQ1A, those who are employed at the time of the survey are asked to imagine that their current employment situations immediately terminate in a manner that does not affect their prospects for future employment. The intention is to make them actively consider post-career employment situations. In SSQ2, they are asked whether they would continue to work in their current job if the characteristics of the job change in the way assumed in the scenarios.

Table C.1: SSQs

\begin{tabular}{|c|c|c|c|c|}
\hline Name & $\underline{\text { Time }}$ & Considered job characteristics & Sample asked & $\underline{\text { Sample size }}$ \\
\hline SSQ 1A & Survey & $\begin{array}{l}\text { Fixed schedule, Flexible schedule } \\
\text { Alternative occupation }\end{array}$ & All & 2,758 \\
\hline SSQ 1B & Retirement & $\begin{array}{l}\text { Fixed schedule, Flexible schedule } \\
\text { Alternative occupation }\end{array}$ & Non-workers & $1,658^{*}$ \\
\hline SSQ 2 & Survey & $\begin{array}{l}\text { Fixed schedule, Flexible schedule } \\
\text { Search after separation allowed } \\
\text { Search after separation not allowed }\end{array}$ & Workers & 754 \\
\hline
\end{tabular}

Notes: Time refers to the reference period of the SSQ, which is either current (time of the survey), or retrospective (time of retirement).

* For those who are retired within the last two years, the survey did not ask SSQ1B because for them the situation at the time of retirement is too similar to that at the time of the survey.

In Section 3.1, we presented details of the scenario offering a job with a fixed schedule at the time of the survey (SSQ1A). In the remainder of this Appendix we present details of the other scenarios, focusing on the differences between the various scenarios.

\section{C.1 SSQ1A: Choices at the Time of the Survey}

\section{Flexible Schedule Scenario}

This scenario is the same as the fixed schedule scenario except that respondents are allowed to choose the number of hours to work. 
- Option $\mathrm{A}$ is a new employment situation that involves a flexible work schedule. Other than this possible difference, it matches your reference employment situation in terms of all other characteristics.

Then respondents are provided with more detailed rules, precisely defining what a flexible work schedule means.

- You can change your regular work schedule at the start of each year but not again until the start of the next year.

- You would have to let your employer know your choice of regular work schedule at the start of the year and you would be expected to meet these work commitments. For example, if you wanted to work half time, you could specify this as half days, or for half as many weeks as usual on a seasonal basis.

- The annual pay is adjusted in proportion (from your reference salary) if you choose to work more or less.

- If you choose option $\mathrm{A}$, there are no restrictions on what you would do with the time that you are not working.

Respondents are then asked about their preferred number of hours per week and number of weeks per year for the following year. The reference salary is adjusted in proportion, and then respondents are asked whether they would accept the offer or not, and then asked to report the reservation wage that makes them indifferent between Option A and B.

\section{Alternative Occupation Scenario}

This scenario starts with the following question:

- Would there be an employment situation with a different occupation that you would prefer to your reference employment situation under any circumstances?

If the answer is no, respondents skip this scenario. If the answer is yes, then Option A becomes:

- Option A is a new employment situation that involves a fixed work schedule in your most preferred alternative occupation. Other than this, the employment situation matches your reference employment situation in terms of annual earnings, as well as in as many other characteristics, to the maximum extent possible.

The remainder of the scenario is identical to the fixed schedule scenario. 


\section{C.2 SSQ1B: Choices at the Time of Retirement}

The structure of SSQ1B is identical to that of SSQ1A except that it concerns choices over hypothetical opportunities if they had been available at the time of retirement from the last job. ${ }^{27}$ SSQ1B starts with the following preamble:

- In the questions that follow, we are interested in the employment situations that might have been of interest to you in the past. Specifically, we will ask you to report the decision you would have made immediately after your reference employment situation ended.

- While it may be hard, we ask you not to answer in light of your current knowledge of what happened since that time, but rather to answer in terms of how you would have behaved if faced with particular employment opportunities at that time. The alternative should be as you would have viewed it at that time, not as you now see it.

Other than the time at which the opportunity was available, there is no difference between SSQ1B and SSQ1A. SSQ1B poses three scenarios, fixed schedule, flexible schedule, and alternative occupation, structured precisely as in SSQ1A.

\section{C.3 SSQ2: Options Allowed for the Current Job}

In SSQ2, the opportunities to be considered involve possible continuation of the current job when its characteristics are altered in various ways. ${ }^{28}$ Not accepting the offer means that the respondent has to quit the current job immediately and pursue other possibilities including searching for another employment situation or not working. In addition to the value of having a flexible schedule, SSQ2 also measures the option value of being able to search for another job opportunity after quitting the current job, by examining how responses change when respondents are allowed versus not allowed to search after quitting the current job. SSQ2 considers four scenarios, (i) fixed schedule not allowing for search after the current job, (ii) flexible schedule not allowing for search after the current job, (iii) fixed schedule allowing for search after the current job, and (iv) flexible schedule allowing for search after the current job.

The first scenario, in which the respondent has to work a fixed schedule and is not allowed to search after the current job if they decided to stay in the current job, is presented as follows:

\footnotetext{
${ }^{27}$ Hence SSQ1B is asked only to the non-workers.

${ }^{28}$ Hence SSQ2 is asked only to those who are currently working.
} 
We are interested in the conditions under which you would want to stay in your reference employment situation with a fixed work schedule. In the following scenario you must decide between keeping your reference employment situation and instead quitting your current employment situation immediately.

More specifically, you must choose between two options:

- Option A is to keep your reference employment situation with a fixed work schedule. You may hold this employment situation for as long as you like. Once you exit this employment situation you can no longer be employed in any other employment situation, and must exit the labor force permanently.

- Option B is instead to pursue other possibilities including searching for another employment situation or not working.

Other scenarios are presented as simple variations of this scenario where the respondent either can work a flexible schedule or is allowed to search after quitting the current job (or both). 


\section{Appendix: Additional Results from the SSQs}

\section{D.1 Full Distribution of Reservation Wages}

This Appendix shows the full distribution of reservations wages for all the SSQ scenarios that are asked to non-workers, separately for those who did and who did not have a bridge job (Figure D.1 for offers at the time of the survey and Figure D.2 for offers at the time of retirement). ${ }^{29}$ Reservation wages are normalized as a fraction of the reference salary. A reservation wage less than or equal to 1 means the respondent accepts the offer. Figures focus on the range of the reservation wages between 0.5 and 1.5. For Panel $\mathrm{C}$ and $\mathrm{D}$, reservation wages under an alternative occupation are plotted only for those who could think of some preferred alternative occupation.

\footnotetext{
${ }^{29}$ Panel A and B of Figure D.1 and D.2 are included in the main text but also presented here for completeness in describing the SSQ results.
} 
Figure D.1: Reservation wage distribution at the time of the survey

A. Fixed vs. flexible schedule: had no bridge job

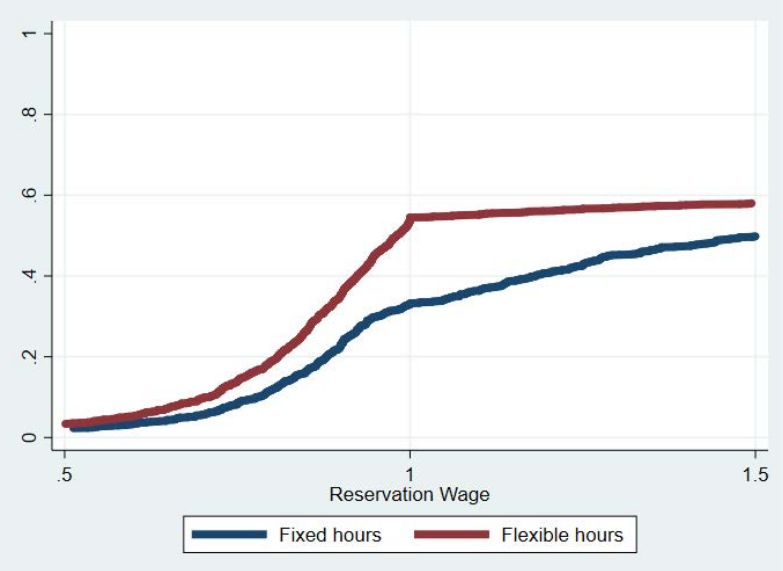

C. Alternative vs. reference job: had no bridge job

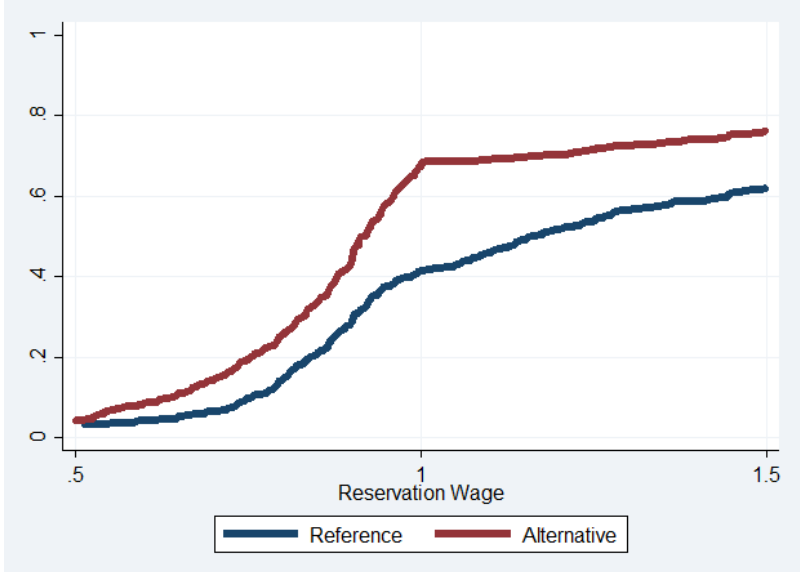

B. Fixed vs. flexible schedule: had a bridge job

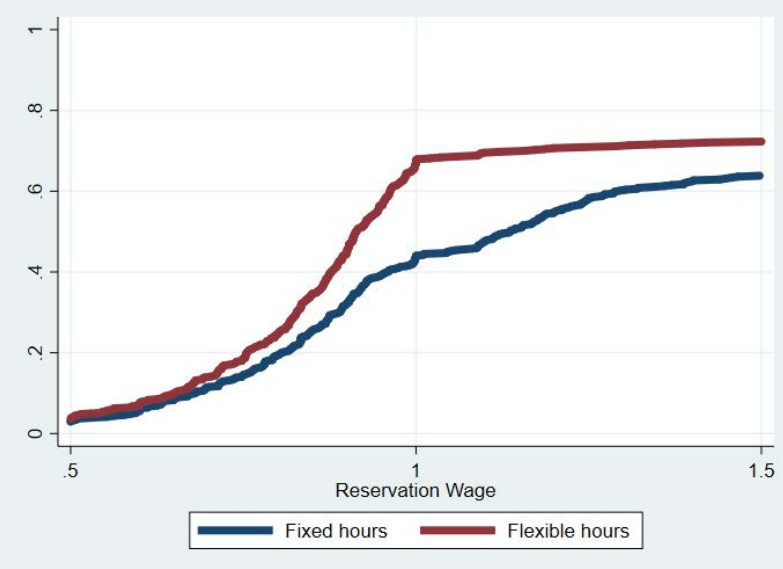

D. Alternative vs. reference job: had a bridge job

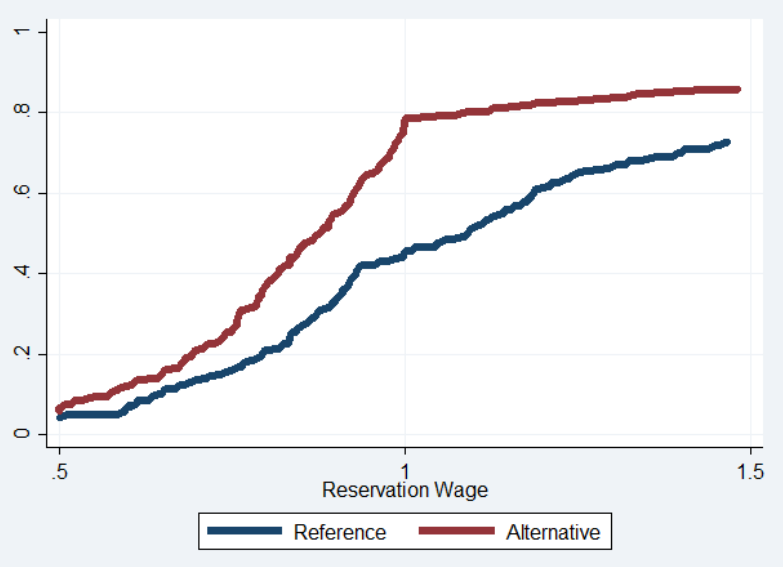

Note: Reservation wage is calculated as a fraction of the wage the respondent had in their reference job. The vertical axis represents CDF. The figure shows the range of reservations wages between 0.5 and 1.5. For Panel $\mathrm{C}$ and D we include only those respondents who could think of any alternative occupation. 
Figure D.2: Reservation wage distribution at the time of retirement

A. Fixed vs. flexible schedule: had no bridge job

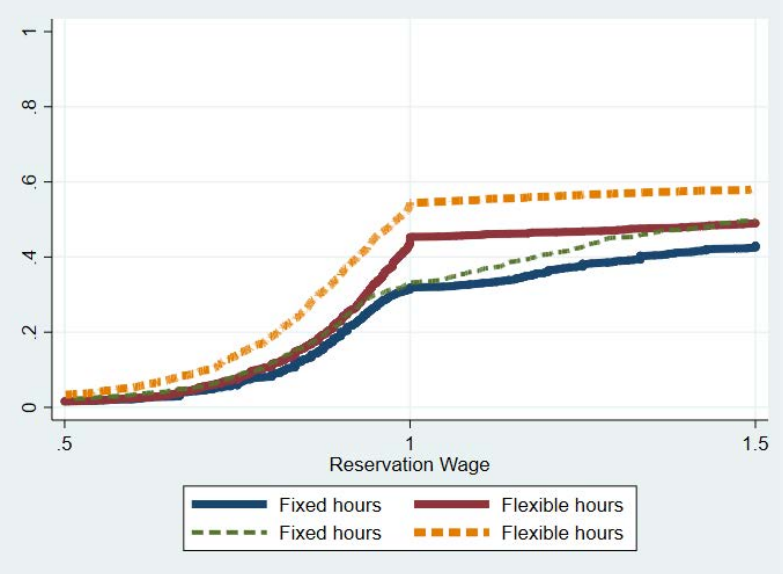

C. Alternative vs. reference job: had no bridge job

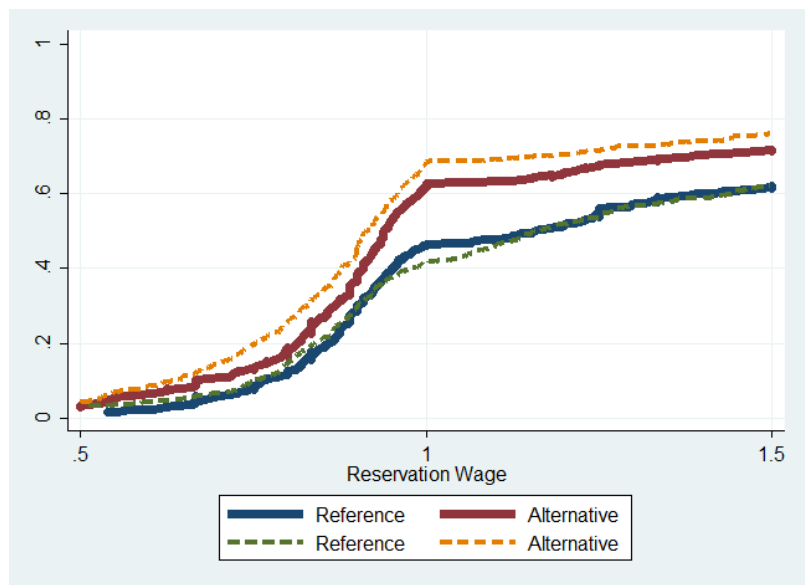

B. Fixed vs. flexible schedule: had a bridge job

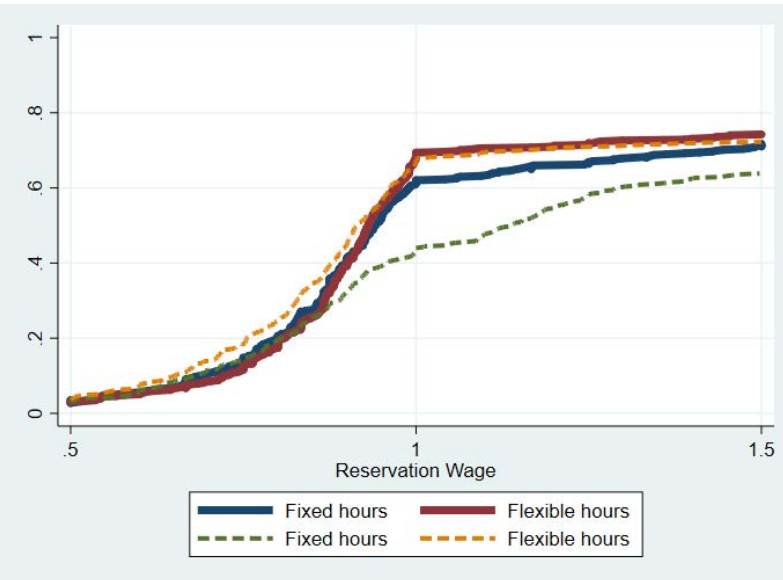

D. Alternative vs. reference job: had a bridge job

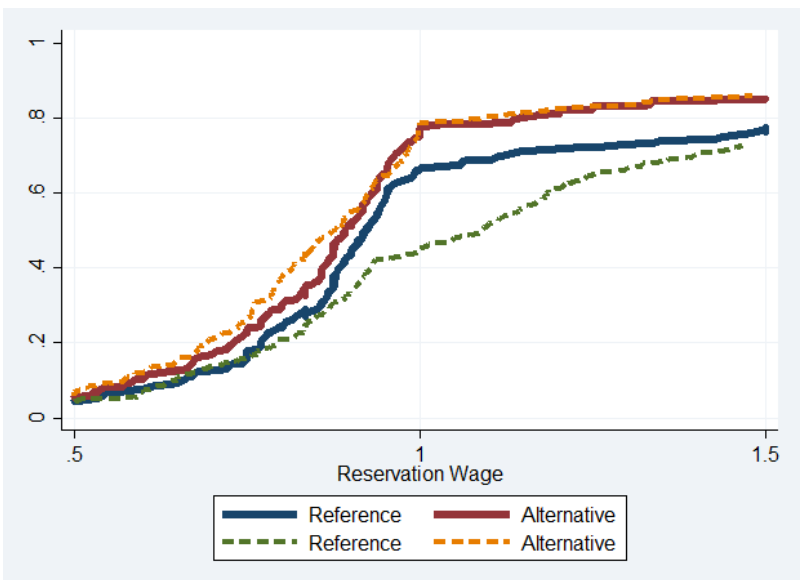

Note: Reservation wage is calculated as a fraction of the wage the respondent had in their reference job. The vertical axis represents CDF. The figure shows the range of reservations wages between 0.5 and 1.5. For Panel $\mathrm{C}$ and $\mathrm{D}$ we include only those respondents who could think of any alternative occupation. The figure also shows the distributions from the offers at the time of the survey for the corresponding scenarios and groups in dashed curves for comparison. 


\section{D.2 IES Estimates under Different Calibrations of Fixed Cost of Work}

In Figure D.3 we show the distribution of the IES estimates under different calibrations: no fixed cost of work in terms of foregone leisure $(\bar{h}=0$ and $\hat{c}=0.14$, Panel A), no fixed expenditure cost of work $(\bar{h}=0.04$ and $\hat{c}=0$, Panel B), and no fixed cost of work at all ( $\bar{h}=0$ and $\hat{c}=0$, Panel C). The estimates tend to be larger in the absence of fixed costs, though the overall pattern of the distribution is not sensitive to the assumed values of fixed costs.

Figure D.3: Distribution of IES estimates: alternative calibrations

A. No fixed leisure cost

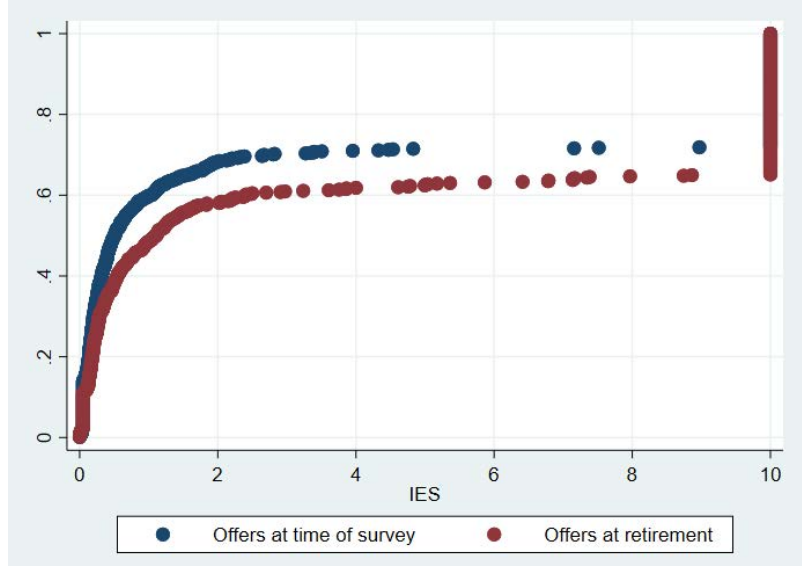

B. No fixed expenditure cost

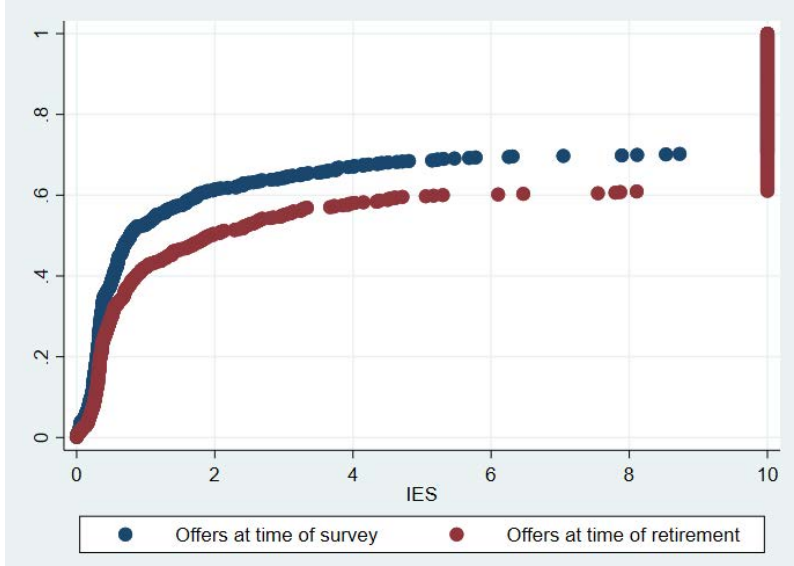

C. No fixed cost

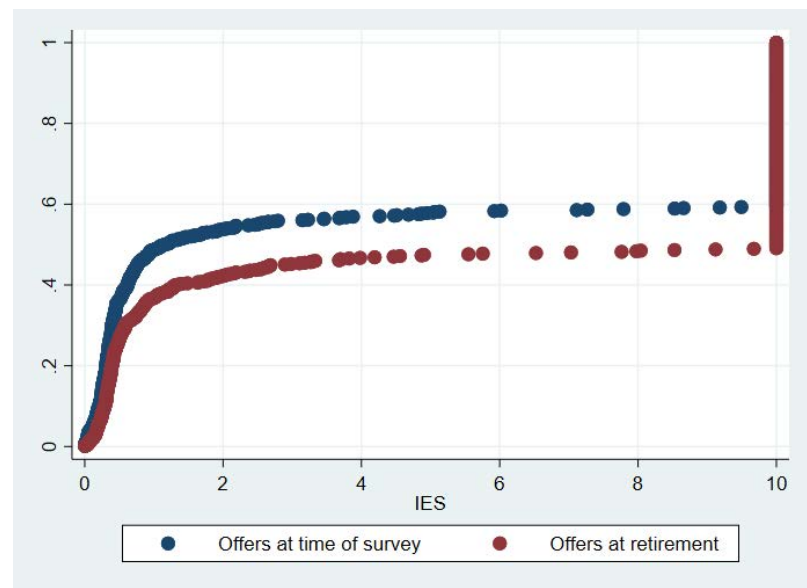

Notes: The curves represent CDFs of the estimated IES. N=796 for SSQ1A and N=668 for SSQ1B. Panel A assumes $\bar{h}=0$ and $\hat{c}=0.14$, Panel B assumes $\bar{h}=0.04$ and $\hat{c}=0$, and Panel $\mathrm{C}$ assumes $\bar{h}=0$ and $\hat{c}=0$.

\section{D.3 IES Estimation under a Nonseparable Utility Function}

In the main text we estimate the IES from SSQ responses assuming a separable utility function between consumption and leisure. In this Appendix we show that the equation used for the estimation is the 
same as equation (9) derived from a nonseparable utility function.

The online Appendix of Rogerson and Wallenius (2013) consider a nonseparable utility function used in Trabandt and Uhlig (2009) and Shimer (2010):

$$
\frac{1}{1-\eta} c^{1-\eta}\left[1-\kappa(1-\eta)(e \bar{h}+h)^{1+\frac{1}{\phi}}\right]^{\eta}
$$

where $\eta, \kappa$, and $\phi$ are all positive. Note that this utility function is different from the one in equation (1) not only in that consumption and leisure are nonseparable but also in that the marginal utility of leisure when $h=0$ is zero. Not to confound the effects of these two differences, we change the above nonseparable utility function to:

$$
\frac{1}{1-\eta} c^{1-\eta}\left[1+\kappa(1-\eta) \frac{(1-e \bar{h}-h)^{1-1 / \gamma}}{1-1 / \gamma}\right]^{\eta}
$$

where the marginal utility from leisure is nonzero when $h=0$ and the IES is $\gamma \frac{1-e \bar{h}-h}{h}$ as in (1). By taking the limit $\eta \rightarrow 1$ after subtracting a constant term $\frac{1}{1-\eta}$, (D.2) becomes the separable utility function used in (1).

As in the main text, suppose that the choices in SSQs do not affect the marginal value of resources $(\lambda)$. The household decides consumption such that the marginal utility from consumption is equal to $\lambda$. Then the optimal current consumption for a household whose labor supply is $h$ is:

$$
c^{*}(h)=\lambda^{-1 / \eta}\left[1+\kappa(1-\eta) \frac{(1-e \bar{h}-h)^{1-1 / \gamma}}{1-1 / \gamma}\right] \text {. }
$$

Plugging this into the utility function, we get the current flow utility for a household whose labor supply is $h$ as:

$$
u\left(c^{*}(h), h\right)=\frac{1}{1-\eta} \lambda^{\frac{-(1-\eta)}{\eta}}\left[1+\kappa(1-\eta) \frac{(1-e \bar{h}-h)^{1-1 / \gamma}}{1-1 / \gamma}\right] .
$$

Then the indifference condition between working for the fixed number of hours and not working can be written as:

$$
\lambda^{\frac{-(1-\eta)}{\eta}} \kappa\left(\frac{1}{1-1 / \gamma}-\frac{\left(1-\bar{h}-h_{\text {fixed }}\right)^{1-1 / \gamma}}{1-1 / \gamma}\right)=\lambda\left(h_{\text {fixed }} w_{\text {fixed }}(1-\hat{c})+c^{*}(0)-c^{*}\left(h_{\text {fixed }}\right)\right)
$$

where the right hand side now takes into account not only the value of additional earnings but also that of any difference in the consumption between when not working and when working $h_{\text {fixed }}$. By plugging (D.3) into (D.5), we get:

$$
\lambda^{\frac{-(1-\eta)}{\eta}} \kappa \eta\left(\frac{1}{1-1 / \gamma}-\frac{\left(1-\bar{h}-h_{\text {fixed }}\right)^{1-1 / \gamma}}{1-1 / \gamma}\right)=\lambda\left(h_{\text {fixed }} w_{\text {fixed }}(1-\hat{c})\right) .
$$

Similarly, the indifference condition between working for the fixed number of hours and working for 
the number of hours chosen by the respondent can be written as:

$$
\lambda^{\frac{-(1-\eta)}{\eta}} \kappa \eta\left(\frac{\left(1-\bar{h}-h_{\text {flex }}\right)^{1-1 / \gamma}}{1-1 / \gamma}-\frac{\left(1-\bar{h}-h_{\text {fixed }}\right)^{1-1 / \gamma}}{1-1 / \gamma}\right)=\lambda\left(h_{\text {fixed }} w_{\text {fixed }}-h_{\text {flex }} w_{\text {flex }}\right) .
$$

Note that equations (D.6) and (D.7) are the same as equations (7) and (8) except for that (D.6) and (D.7) have $\lambda^{\frac{-(1-\eta)}{\eta}} \kappa \eta$ instead of $\alpha_{t}$ multiplied on the left hand side. But this is a term that cancels out when dividing one indifference condition by the other, so in the end the equation used for estimation is the same equation (9).

In addition, one can easily show that the relationship between the necessary nonconvexity in production to explain an abrupt retirement and the IES is not affected by introducing nonseparability in the utility function. If we redo the exercise in online Appendix C of Rogerson and Wallenius (2013) using (D.2) instead of (D.1), we find that the condition for the minimum value of $\theta$ required to generate an abrupt retirement is exactly the same as equation (6). 


\section{E Appendix: Additional Robustness and Credibility Checks on the SSQ responses}

This Appendix reports results from the additional tests on robustness and credibility of the SSQ responses that are not reported in the main text. The first test shows external consistency of the SSQ responses under the alternative occupation scenario by comparing them to actual search behavior. The next two tests confirm internal consistency of the SSQ responses. The last test confirms understanding of the hypothetical situation by reporting results from the comprehension tests that were implemented during the survey.

\section{E.1 Search Behaviors and SSQ Responses: Alternative Occupation}

We find consistency between the responses to the SSQs under the alternative occupation scenario and actual search behavior. Those who actually looked for a job either in a different occupation or a different industry are more likely to accept the offer in the SSQ that allows for an alternative occupation. ${ }^{30}$ As a result, the impact of allowing for an alternative occupation on the acceptance rate is the largest for this group.

Table E.1: Search behaviors and SSQ responses: Alternative Occupation

\begin{tabular}{|c|c|c|c|}
\hline \multirow[b]{2}{*}{ Searched for } & \multirow[t]{2}{*}{$\mathbf{N}$} & \multicolumn{2}{|c|}{ Acceptance rate } \\
\hline & & $\begin{array}{c}\text { Reference } \\
\text { occupation }\end{array}$ & $\begin{array}{l}\text { Alternative } \\
\text { occupation }\end{array}$ \\
\hline Did not search & 1,188 & 33.7 & 26.2 \\
\hline Alternative occupation/industry & 53 & 39.6 & 47.2 \\
\hline Other than alternative occupation/industry & 94 & 30.9 & 33.0 \\
\hline
\end{tabular}

Notes: The tabulation includes only retirees who did not have a bridge job. In calculating the acceptance rate for an alternative occupation scenario, those who cannot think of any alternative occupation are considered as not accepting the job. Hence the acceptance rate is calculated as the multiplication of two probabilities: whether they can think of a preferred alternative occupation and whether they will accept the offer made in the preferred occupation.

\section{E.2 Consistency in Responses}

The SSQs ask about the same types of job but differ in the timing of the offer: one at the time of the survey and the other at the time of retirement. If the responses truly reflect the respondents' preferences, we expect there to be a positive correlation between the responses for the same job characteristics offered at different times.

For both fixed and flexible schedule scenarios, the extensive margin choices are strongly positively correlated between the SSQs asked at different times. If a respondent accepts the offer at the time of

\footnotetext{
${ }^{30}$ Those who cannot think of an alternative occupation are included as not accepting an offer in that scenario.
} 
the survey then he is more likely to do the same at the time of retirement. The correlation between the responses to the offers at different times is 0.42 for a fixed schedule scenario and 0.45 for a flexible schedule scenario, where the t-statistic for the null of no correlation is 19.7 for the former and 21.1 for the latter.

\section{E.3 Reasonableness of Responses}

If the response switches from accept to do not accept when we make the offer more attractive either by allowing for a flexible schedule or an alternative occupation under the same level of offered salary, then it can be considered unreasonable. In Table E.2, we calculate the share of unreasonable responses, in various questions.

We find that the share of unreasonable responses is small. It is less than 4 percent under any comparison. The share is still small even when we consider only the switchers, defined as responses that change at the extensive margin between the two scenarios considered. For each comparison, between one fifth to a quarter of respondents switched their responses. More than $80 \%$ of switchers switch in the expected direction, in all cases.

Table E.2: Reasonable Responses: Share of unreasonable changes in responses (\%)

\begin{tabular}{|c|c|c|}
\hline \multirow[b]{3}{*}{ Time of the survey } & \multicolumn{2}{|c|}{ Share of unreasonable changes in responses } \\
\hline & Among all responses & Among switchers \\
\hline & & \\
\hline$\overline{\text { Allowing for flexible schedule }}$ & 1.9 & 7.9 \\
\hline Allowing for alternative occupation & 1.7 & 6.1 \\
\hline Time of retirement & & \\
\hline Allowing for flexible schedule & 3.3 & 18.8 \\
\hline Allowing for alternative occupation & 3.5 & 16.6 \\
\hline
\end{tabular}

Note: Switchers are defined as those who change their responses between the two scenarios considered.

\section{E.4 Comprehension Test Results}

Given the intensive use of hypothetical situations in the SSQs, it is important to check whether the respondents fully understood the assumed scenarios before they answered the SSQs. Whenever the survey introduces a new type of scenario, it asks a set of comprehension tests to verify that respondents understood the assumed scenario and associated rules correctly. If the respondents do not correctly answer all questions on their first try, the questions they missed are repeated. If they incorrectly answer any questions on their second try, they are told the correct answer.

Table E.3 summarizes the results of the comprehension tests (the number of questions correctly answered after their second try). Median respondents answer almost all questions correctly even on their first try. On their second try, respondents rarely miss any of the questions. This confirms that 
the respondents were paying attention during the survey and they did not have much difficulty in understanding the assumed hypothetical scenarios.

Table E.3: Comprehension test results

\begin{tabular}{|c|c|c|c|c|c|c|}
\hline & $\underline{10 p}$ & $\underline{25 p}$ & $\underline{50 p}$ & $75 p$ & $90 p$ & $\underline{\mathbf{N}}$ \\
\hline \multicolumn{7}{|c|}{ Fixed schedule (Best score: 7 for married and 6 for singles) } \\
\hline First trial (married) & 3 & 4 & 6 & 6 & 7 & 1,835 \\
\hline Second trial (married) & 5 & 6 & 7 & 7 & 7 & 1,835 \\
\hline First trial (singles) & 3 & 4 & 5 & 6 & 6 & 923 \\
\hline Second trial (singles) & 5 & 5 & 6 & 6 & 6 & 923 \\
\hline \multicolumn{5}{|l|}{ Flexible schedule } & \multicolumn{2}{|c|}{ (Best score: 4 ) } \\
\hline First trial & 2 & 3 & 4 & 4 & 4 & 2,757 \\
\hline Second trial & 3 & 4 & 4 & 4 & 4 & 2,757 \\
\hline \multicolumn{5}{|c|}{ Alternative occupation } & \multicolumn{2}{|c|}{ (Best score: 3 ) } \\
\hline First trial & 2 & 2 & 3 & 3 & 3 & 1,264 \\
\hline Second trial & 3 & 3 & 3 & 3 & 3 & 1,264 \\
\hline
\end{tabular}

Note: Table shows the number of correct answers from the comprehension tests for the first and second trials. Best score is the total number of questions asked and it varies across scenarios. Married are respondents who are married or in a relationship sharing financial decisionmaking. For the fixed schedule scenario the best score is different between married and single respondents as the test asked one more question to the married respondents. 